\title{
A HOARD OF SAMIAN WARE FROM POMPEII.
}

\author{
(Plates II-XVI). ${ }^{1}$
}

By DONALD ATKINSON.

During a visit to Naples in June, I9I3, I was permitted by the courtesy of Professor Spinazzola, the distinguished Director of the National Museum, to examine a number of decorated bowls of Samian ware obviously of south Gallic style, preserved in the ' magazzini ' of the museum. Professor Spinazzola most kindly afforded me every facility for their study, and consented to their publication. Seventy-six of these bowls bore, in addition to the inventorynumber, the date $\mathrm{I} 882$, and a subsequent reference to three passages in the Notizie degli Scavi ${ }^{2}$ made it possible to identify ninety bowls in all as belonging to a group found together at Pompeii. The circumstances of the discovery were as follows : the ninety bowls were found on 4th October, 1881, in the 'tablinum' of house 9, insula 5, region viii (ii). They were arranged in order in a wooden box, of which some charred fragments remained, together with thirty-seven earthenware lamps said to have shewn no sign of use. Of these lamps twenty-four bear the stamp strobili; six, Comvnis; four, EсHIO ; two, FORTIS ; and one is uninscribed. Side by side with this box were found two others, containing red powder, either pounded brick or red earth, the use of which I do not know.

Further discoveries recorded from this house are not such as to show the nature of its occupation. They consist of domestic furniture, a spade, half of a saw and seventeen stamped amphorae, and they indicate that it was inhabited when it was overwhelmed in August, 79.

The first of the passages from the Notizie cited above, gives a description of thirty-seven bowls, which were intact or only slightly broken; the third deals with the remaining fifty-three, which presumably had been repaired in the interval. The descriptions are brief and somewhat vague, they rarely mention the fact that the bowls are stamped, and they give only five of the actual stamps; but they happen to record the diameter of each bowl, and the agreement of these measurements with those taken by the present

\footnotetext{
1 The drawings used to illustrate this article were made by my colleague, Mr. C. C. Pearce of University College, Reading, from pencil rubbings which I took from the original bowls in the Naples Museum while studying in Italy as Pelham Student of the University of Oxford. I wish to express here my thanks to him for the care and patience which he
}

bestowed on a difficult and tedious task. My thanks are also due to the University of Oxford for further defraying, by a grant from the Craven Fund, the cost of preparing the drawings.

${ }^{2}$ Not. Scav. 1881, pp. 300 , f. and $322 ; 1882$, p. 275 , f. 
writer confirms in every case the identification suggested by the description of the decoration, and by the numbers attached to the bowls themselves. ${ }^{1}$

The bowls are all completely preserved. Many of them show clear signs of fire. Some are burned black all over, both inside and out; while others present a mottled appearance, partly red and partly black. No mark of wear was to be observed on the bases, some of which showed slight roughness such as would soon have been rubbed smooth by continuous use.

The discovery of so many bowls, more, one may presume, than would supply the needs of a single household, packed carefully together and associated with unused lamps, seems strongly to suggest that they represent a consignment lately received in Pompeii from a wholesale dealer in such wares. The presence of lamps of Fortis and Comunis, whose factories are usually assigned to northern Italy, ${ }^{2}$ indicates that the bowls did not reach Pompeii direct from their place of manufacture in southern Gaul.

If this hypothesis be accepted, and it does not seem inconsistent with the circumstances of the discovery or, as it is hoped will be shown below, with the character of the bowls themselves, the date of their manufacture can be fixed within narrow limits, to a time indeed to be reckoned by months before the destruction of Pompeii. For this reason they possess exceptional value as material for comparison with Samian ware found on other sites. Too often it is the case that, if the beginning or the end of the occupation of a site can be accurately dated, the other limit of time is much less definitely fixed, or the occupation-period is too long to supply evidence for the accurate dating of the objects found. Thus, at Rottweil, it is safe to assume that the Samian is later than the year 74, but it would be rash to assert that all or even most of the south Gallic ware found there belongs to the next decade; while at Pompeii two bowls of form 29 have been found, one with the stamp GERMANI (no. $\frac{12}{\text { vii }_{3}} 62$ ), the other of marbled ware with an illegible stamp (no. r6290), which seems to agree in decoration better with a Neronian than with a Flavian date.

If, however, this accurate dating, roughly between 77 and 79 , be accepted, the large proportion of bowls of form 37 (form 29, thirty-six bowls; form 37, fifty-four) cannot be used to invalidate conclusions based on other evidence as to the relative commonness of the two forms in the years 70-80. Apart from the present hoard, the writer examined twenty-eight similar bowls at Naples and Pompeii; of these twenty-six were of form 29 and

1 The 37 bowls of the first group are numbered
consecutively from I I 2892 , I/1882, to I 12928 ,
$37 / 1882$, the remaining 53 from I I 2966 to I 13018 ,
127/1882, the intervening numbers being no doubt assigned to the 37 lamps.

${ }^{2}$ Ritterling, Hofbeim, 1913, pp. 269 and 321 , foot-note. 
two of form 37. There are further four pieces of form 29 from Pompeii in the British Museum, ${ }^{1}$ and Knorr figures a fifth fragment of the same form now in Stuttgart. ${ }^{2}$ Of the five bowls of form 37 recorded by Déchelette, ${ }^{3}$ two, nos. 16 and 18 , belong to this hoard and are numbered 84 and $68 .^{4}$ The proportions, therefore are form 29, thirty-one; form 37, three. With this may be compared the case of Hofheim, where a considerable number of pieces of form 29 of the Flavian period were accompanied by only four or five of form $37 .^{5}$ It is probable then that form 37 did not become common until the latest years of the decade $70-80$. The complete absence of form 30 at Pompeii is remarkable, for, though it was less commonly used at this time than in the period $40-70,{ }^{6}$ a considerable number of fragments have been found at Rottweil, in London, and elsewhere.

The thirty-six bowls of form 29 all bear stamps in the centre inside, and two of them, nos. 2 and 15 , also among the decoration. They are distributed among the potters represented as follows:

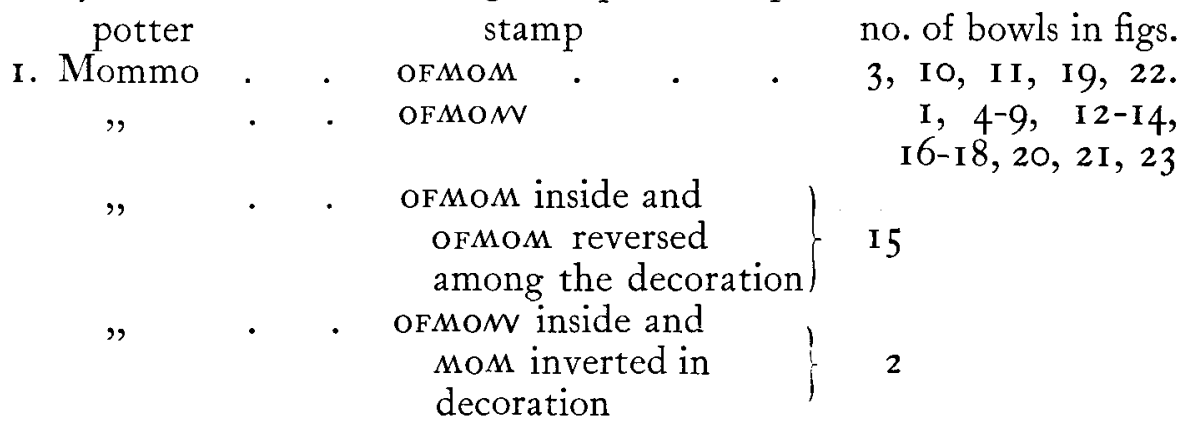

\begin{tabular}{|c|c|c|c|}
\hline 2. Vitalis & $\mathrm{OFVI}$ & & $26-30$ \\
\hline 3. Manduillus & MNDVIXM ${ }^{7}$ & & $3 \mathrm{I}, 32$ \\
\hline 4. Rufinus & OFRVFINI & & 35,36 \\
\hline 5. Patricius & OF.PARICI & & 34 \\
\hline 6. Secundus ? & OFSCVN & & 24 \\
\hline 7. Mo(ntici ?) & OFMOHIIC: & & 33 \\
\hline ? & illegible & & 25 \\
\hline
\end{tabular}

${ }^{1}$ Cat. p. 4 , M. $7^{-10}$

${ }^{2}$ Rottenburg, i, 7 .

3 vol. i, p. 95 , f.

4 Déchelette's no. I9 I failed to find.

${ }^{5}$ Ritterling, Hotbeim, 1913, p. 23 If.

It is convenient to give here the dates of the occupation of some sites frequently referred to below. site. date.

The Sels brickworks (Neuss) . Almost all the finds earlier than $4 \mathrm{r}$.

$\begin{array}{ccc}\text { Wiesbaden (early stratum) } & \text { 37-69. } \\ \text { Flavian }\end{array}$

Hofheim (early period . . 41-5I.

$"$ (later period) : $\quad 74-80-83$.

Rottenburg • • . $\quad 80-$

Windisch $\quad \cdot \quad \cdot \quad \cdot$ chiefly Flavian.

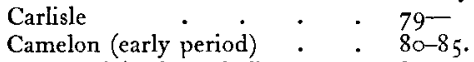

Newstead (early period) . . 80-100 (?)

These dates are in most cases to be taken as only approximate. The end of the early period at Newstead is uncertain. There is some evidence that the site was occupied for some years after the recall of Agricola, but probably not beyond the very earliest years of the second century.

${ }^{6}$ For its prevalence in the period $40-5 \circ \mathrm{cf}$. Ritterling, Hofbeim, I913, p. 225 and Taff. xxvi and xxvii.

7 The left stroke of the penultimate letter is straight in the actual stamp. 
The bowl no. 34 with the stamp of Patricius has also traces of curcive letters which were incised in the mould. They are partly obscured by the foot-ring and are illegible, but enough remains to make it almost certain that the name was not that stamped inside. It may fairly be assumed that we have here an instance of a practice observed elsewhere, by which the mould of one potter was acquired and used by another. ${ }^{1}$

The stamps on the bowls of form 37 are distributed as follows : potter stamp no. of bowls in figs.

I. Memor . cursive letters incised in the mould upsidedown under the decoration (plate xIv) $.73,74$

2. Mommo . cursive letters incised in the mould under the decoration $^{2}$ (plate $\mathrm{xI}$ ) . . . .

3. Mo(destus ?) letters from right to left incised on a raised

label among the decoration om 70 (plate xiII)

Besides these four, there are traces of letters, mostly concealed by the foot-ring, on no. 59. Though nearly illegible, the form of what remains visible is not inconsistent with the stamp of Mommo, and the decoration also suggests the attribution of the bowl to that potter (see below, p. 57). Slight remains of letters seemed to occur also on no. 45 , but they were so faint and vague that nothing could be inferred from them.

\section{DECORATION ON FORM 29.}

The decoration of the bowls of form 29 shews in general arrangement a later type than other bowls from Pompeii. Of the thirtyone bowls referred to above (p. 29), only two have a lower frieze divided into metopes; the majority bear purely ornamental designs, resembling the earliest fragments at Rottweil, and pieces. from the legionary camp at Xanten (Vetera) and other sites occupied under Nero. On the other hand, of the twenty-three bowls of Mommo here represented, as many as fourteen have metopes ${ }^{3}$ in the lower frieze, as have both of the bowls of Manduillus, one of Rufinus and the one with the stamp Mo(ntici ?), while the other bowl of Rufinus has a band of animals and grass-plants. Thus, on one half of the bowls of

\footnotetext{
${ }^{1}$ cf. Knorr, Rottweil, I9o7, Taf. xxvii, 9, where a bowl with the stamp of Reginus among the decoration has the stamp IVTAEVs.F on the smooth rim.

2 The same cursive stamp occurs on two moulds figured by Déchelette (i, p, 8o, figs. 5, 9 and 6o) and on a fragment of form $2 g$ in the Museo delle Terme at Rome.

${ }^{3}$ An explanation is perhaps needed of the use of this term in the following pages. The expression "décor à metopes" was first used by Déchelette,
}

and describes accurately enough the upper frieze of a bowl of form 29 divided by vertical zigzag lines into small rectangular spaces containing alternately a group of figures and an ornamental design such as "arrowheads." The meaning of the phrase is, however, extended to cover any decoration in which the field is divided into compartments by vertical lines, regardless of the fact that such an arrangement in the lower frieze quite ceases to bear any resemblance to the architectural feature from which the name is borrowed. 
form 29 the ornamentation is probably influenced to some extent by the decoration of form 37. This tendency to metope decoration becomes more marked in the latest bowls of form 29 , such as occur on the Agricolan sites in the north of Britain. ${ }^{1}$

\section{MOMMO.}

(PLATES I-V).

Mommo, to whom we may attribute not only the twenty-three bowls of form 29 but also ten of form 37 (see below, p. 39), has been shown by Déchelette to rank among the most prolific of the southern Gallic potters. His name occurs on three out of the four signed moulds, and on fifty-five bowls or fragments found at $\mathrm{La}$ Graufesenque, and it is attached to the largest number of vessels $(9,000)$ mentioned on the 'graffiti' found there. ${ }^{2}$ The period of his activity seems to have been long. The earliest form of his stamp, $\odot \odot,^{3}$ occurs several times on plain vessels of the earliest forms (e.g. types 8 and 9 of the Hofheim series), in the Sels collection at Neuss, and on form 24 at Hofheim, so that this stamp may be dated with much probability to the period A.D. 30-50. Plain vessels with one or other of his stamps occur frequently in all parts of Gaul and in Germany, e.g. at Rottweil, Risstissen, Gunzburg and Aislingen, ${ }^{4}$ and even in Britain : they occur in London on forms 18 , 27,33 , at Colchester on form 27, at Kettering on form 24, and at Carlisle. Of the distribution of his decorated wares less is known. Besides those from La Graufesenque and Pompeii, there is a fragment of form 29 in the Museo delle Terme at Rome (see note 2, p. 30, above), and Déchelette ${ }^{5}$ gives a list of a number found in south Gaul.

Hitherto, so few bowls of this potter have been published that it has been impossible to assign him to any group of potters. These pieces from Pompiii now make it clear that he belongs to the circle of Vitalis, Germanus, Crestus, Meddilus, Sabinus, Rufinus, Patricius and Manduillus. All these potters, except the last two, are grouped together by Knorr, ${ }^{6}$ with the addition of Crucuro and Biracil. There is, however, reason for placing these two last a little later ; they seem, indeed, to belong to the Domitian-Trajan period rather than to the reign of Vespasian, wherever they can be dated. It is interesting that a small group of pots found together at Wroxeter contained the stamps of Vitalis, Mommo, Patricius and Cotous. ${ }^{7}$

\footnotetext{
1 For these bowls compare Bushe-Fox in Arcbacologia, lxiv, 295, f.

${ }^{2}$ Déchelette, i, 86 f. 287 , f.

${ }^{3}$ cf. Ritterling, Hofbeim, 1913, Taf. xxii, no. 216.

4 cf. C.I.L. xiii, part 3 , i, 10010, 1374 .
}

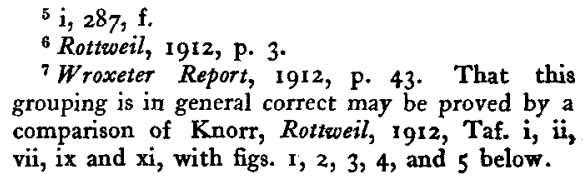

'Wroxeter Report, 1912, p. 43. That this grouping is in general correct may be proved by a comparison of Knorr, Rottweil, 1912, Taf. i, ii, vii, ix and xi, with figs. $1,2,3,4$, and 5 below. 
The bowls of Mommo in the present find show much carelessness in technique. The spacing is in some examples so inaccurate that it has been necessary to vary considerably the size of the metopes; and in some cases the freehand drawing of the stems of leaves and tendrils is far from good, as is particularly noticeable in no. I6. The lower frieze of no. 17 has suffered some accident, perhaps the moring of the clay in the mould, and the design is stamped twice in such a way as almost entirely to obscure its details. The 'godroons' of the lower frieze on no. 22 show the same defect in a lesser degree, while in nos. 16 and 21 the attachment of the rim has destroyed the upper part of the rinceau. Often the relief is very flat, and much of the detail has been lost through the wearing of the mould. Throughout the whole hoard it is noticeable that the figure-types are on the whole consistently smaller than the corresponding types shown in Déchelette's pages, and that in a number of instances they are actually reduced copies of types which occur on signed bowls of earlier potters. Thus the animals of the upper frieze of no. 13 are identical in everything but size with those on a bowl of Masclus at Vienna ${ }^{1}$ which may be dated to the reign of Claudius.

VITALIS.

(PLATES v, vi).

The decoration of all the five bowls of Vitalis (nos. 26-30) consists of purely ornamental designs. All but one have details which occur on the bowls of Mommo, but the workmanship is in every case much superior. The moulds are well made and the impression sharp, so that the smallest details are clearly visible; only in one case, no. 30 , is there any defect in the regularity of the design. The beginning of the activity of this potter is determined by the occurrence of his stamps in the earlier stratum at Wiesbaden and by their absence in the early period at Hofheim; he started in the reign of Nero, but there is no doubt that most of his wares were in use in the Flavian period. His stamps occur more frequently in the Flavian stratum at Wiesbaden, five times in the Vespasianic fort at Hofheim, and at least twenty-five times at Rottweil ; they are common also at Windisch. ${ }^{2}$ Decorated bowls with his stamp occur at Poitiers, Rome, Carthage, London, ${ }^{3}$ Nijmegen, Carlisle, ${ }^{4}$ and Newstead, 5 while his plain wares are found commonly in Germany, Gaul and Britain. ${ }^{6}$

Neither the decoration of his bowls nor the circumstances of their discovery, however, allow us to class him among the latest

1 cf. Knorr, Rottweil, 1907, xiii, 2.

2 Ritterling, Hofbein, I9I3, p. 249, f.

3 Déchelette, i, p. $3 \circ 3$.

\footnotetext{
${ }^{4}$ Bushe-Fox, p. $30 \mathrm{r}$.

${ }^{5}$ Report, p. 242.

${ }^{6}$ C.I.L. xiii, pt. 3 , i, 100010, 2062.
} 
south Gallic potters with Biracil, L. Cosius, Crucuro, Mercator, etc. and his activity probably ended by or soon after the year $85 .^{1}$ As none of the bowls of Vitalis or of the other potters represented in our Pompeian deposit, except those of Mommo, bear a stamp on the moulded part, it is not certain that these potters actually made the moulds which they used. It may be that the close connexion between them is due to a common use of moulds made by one of them rather than to the use of the same poinçons for each to make his own mould. The bowl of Patricius, mentioned above (p. 30), seems to point in this direction.

\section{MANDUILLUS.}

(Plate VI).

The two bowls of Manduillus ${ }^{2}$ (nos. $3 \mathrm{I}$ and 32 ), are connected by the details and arrangement of their decoration with those of Mommo (cf. especially $3 \mathrm{I}$ with $\mathrm{IO}$ and I2). Stamps of this potter are not frequent. Two, both on form 18 , occur at Hofheim, though to which period of that fort they belong there is no evidence to show. One was found in the earlier stratum at Wiesbaden, and Déchelette gives one from La Graufesenque. ${ }^{3}$ The stamp was also found at Wroxeter in 19I3. The Wiesbaden example shows that Manduillus began to work under Nero: we have no evidence to show how long his activity continued.

\section{RUFINUS.}

(Plates VI, VII).

The bowls of Rufinus (nos. 35 and 36 ) are very much alike and are both connected with some of the bowls of Mommo. ${ }^{4}$ His stamp occurs on several sites otherwise connected with the Flavian period, five times at Rottweil, ${ }^{5}$ once at Carlisle, and once at Camelon, ${ }^{6}$ all on form 29. He is found once in the later period at Hofheim, while the appearance of a stamp in the earlier stratum at Wiesbaden suggests that he began to work before A.D. 69. The bowls at Carlisle and Camelon carry his date into the ninth decade of the century. The evidence implies that the beginning and end of his period coincide with that of Vitalis, as Knorr asserts. ${ }^{7}$

\footnotetext{
${ }^{1}$ Knorr, Das Kastell Ristissen, in Festscbrift der K. Altertümer-Sammlung in Stutgart, 1912, p. 57 , where the date $60-8_{3}$ or $8_{5}$ is suggested.

2 The name occurs on Gaulish tombstones which suggest that it should be spelt Manduillus. On Samian it always appears abbreviated.

$s$ There are also two stamps in the British
}

Museum, Cat. M. 812 on form 27, and M 942 on form 33, but neither of them can be attributed with certainty to this potter.

4 cf. no. 35 and no. 6 .

' Knorr, Rottweil, r907, p. 65, Taf. i, 8.

6 Bushe-Fox, p. 300 and 308.

'Festscbrift, p. 57 . 


\section{PATRICIUS.}

(Plate vi).

The bowl of Patricius, no. 34, also has details which occur on the bowls of Mommo. ${ }^{1}$ While the upper frieze of the bowl is clear and sharp, the flat relief and blurred outlines of the lower suggest that the mould was badly made or had already seen a good deal of service when the present bowl was produced. The stamp of this potter occurs twice in the later period at Hofheim, often at Wiesbaden, especially in the later stratum, and in the Sels collection at Neuss where it is to be assigned to a period later than most of the Sels pieces. Déchelette ${ }^{2}$ cites two examples from La Graufesenque and Nìmes, both of form 29, and it is found on the same form at Ostia. On plain ware it appears often in Gaul and Germany, and in England not infrequently (e.g. at Carlisle). Knorr ${ }^{3}$ places the activity of Patricius between the years 50 and $70-73$ but the latter date is shown by the Carlisle stamp to be too early. Nor does there seem sufficient evidence for putting the beginning of his period before the later years of Nero. The years $60-80$ or 85 may be suggested as a more probable dating.

\section{DOUBTFUL.}

The stamps of our other three bowls of form 29, nos. 24, 25 and 33 , could not be read with certainty. No. 24 seemed to be ofscrn (not ofsecve) : it may be a stamp of Secundus, for of the various potters of this name one may belong to this period, but no stamp without an $\mathrm{E}$ is assigned to him in the Corpus, nor can I find any parallel anywhere by which one might arrive at a definite conclusion. The present bowl has some details which recur on those of Mommo. The workmanship is in general good but there is an error in the spacing of the rinceau of the upper frieze. The stamp of no. 25 is quite illegible. The decoration of both friezes is very much blurred, and the rim is carelessly set on so that part of the rinceau is destroyed. There is nothing in the decoration to connect it with any other bowls in the hoard. No. 33 has a stamp of which only the first letters are plain, ofmomllon, while there might be a c almost at the end of the stamp. It is possible that it should be read of MonTICI or OFMONT.CL, a stamp which occurs with some frequency at Windisch in this period and is found elsewhere. ${ }^{4}$ The bowl is small and the decoration mean and inartistic to a greater degree than in any other of the hoard. The animal types are found on bowls of Mommo and Rufinus.

iff. nos. $9,10,11,16$ and 17.
$2_{i}, 294$.
${ }^{3}$ Festscbrift, p. 57 .

${ }^{4}$ C.I.L. xiii, pt. 3 , i, 10010, $137^{8-9}$. 
DECORATION ON FORM 37 .

Of the fifty-four bowls of form 37, thirty-five bear decoration arranged in zones or friezes conforming more or less closely to Déchelette's first class (i, 100, "décor de transition "), though in some the change to the second has almost come about. In such bowls as 64,66 and $8 \mathrm{I}$, the main element in the decoration is a series of narrow metopes containing figures. There is, however, still a wreath above or below the metopes or in both places, and the metopes themselves are still no wider than would serve to fill the upper frieze of a bowl of form 29. The proportion of figure-subjects is large. Only ten of these thirty-five bowls have exclusively ornamental designs. There are signs, however, that the metope-decoration was still something of a novelty when these bowls were made. Thus divided metopes which so often appear on the latest productions of south Gallic activity occur on eight of our bowls, but they are sparingly used and are in nearly every case associated with arrowheads. The developed type, as it is found on bowls of Mercator or L. Cosius, is here only found on no. 50, where a lion runs immediately above the head of Minerva. The decoration almost always shows signs of intelligent arrangement, and the relative size of the figures is usually maintained, though no. $5 \mathrm{I}$ with a hare twice as big as a stag is an exception.

There is, too, a complete absence of the unintelligent use in metopes of designs only suitable for continuous friezes, a type of decoration which became increasingly common later, when a single festoon, or sometimes a pair, would be used to fill a space in a scheme of figure-decoration. This fault is exemplified in several bowls from the Bregenz cellar-find. ${ }^{1}$ In these later bowls, too, the grouping is almost always quite haphazard, whereas, with one or two exceptions, a certain suitability in the choice of associated subjects is visible in the present hoard. It is perhaps worth observing that the small grass-plants, sometimes placed one above another, which form so common a feature of the later bowls, are never found here. Obviously their presence on a bowl may be held to be a strong reason for assigning it to the reign of Domitian or later. Knorr ${ }^{2}$ describes it as characteristic of the period of Vespasian and Domitian; but of the potters, Masculus (stamp ofmascvi), Biracil and Paullus, whose signed bowls bear this ornamentation, the first two belong certainly rather to the reign of Domitian than to that of Vespasian, and the activity of Paullus might easily have continued as long. ${ }^{3}$

1 Fabrbucb für Altertumskunde, vol. vi (1912), p. ${ }^{172} \mathrm{f}$.

${ }^{2}$ Rottweil, I912, p. 4 .
${ }^{3} \mathrm{cf}$. the bowl of Paullus (Knorr, Rottweil, 1907, Taf. xiv, 7, where the divided metope style is fully developed). 
The tiny ornaments used in rinceaux to cover the points of divergence from the main stem of leaves and tendrils are almost always, when they can be made out with certainty, of the type figured by Knorr, Rottweil, I912, Taf. i, I6. A few are larger and coarser, and some have five or six rings instead of the orthodox four. In very many cases the mould was not sharp enough to permit the form to be accurately drawn. No case exists of the earlier type of two tiny diverging leaves, ${ }^{1}$ for the example on no. $2 \mathrm{I}$, though similar, is not identical.

It is clear, from the connexion which has been shown to exist between the decoration of stamped bowls of different potters, that it would be impossible from a consideration of the arrangement of the decoration, or of the details which compose it, to assign with any degree of certainty those which bear no stamp to any one potter. It is possible, however, that in the case of bowls of form 37, the ovolo which almost invariably forms the upper border of the decoration may prove of considerable assistance in attempting to assign to single potters bowls of this period, as it has been in the case of Aretine vases ${ }^{2}$ and of the later German fabrics. Every maker of moulds of this form must have had a poinçon for this part of the decoration in constant use, and the evidence goes to show that the ovolo used by a potter was not readily changed. That the same one lasted a potter throughout his career is, on general gounds, unlikely, and is disproved by such cases as that of the potter Cibisus who had at least three. ${ }^{3}$ But all the bowls with the stamp of Germanus bear the same ovolo ${ }^{4}$; the two bowls of Memor, nos. 73 and 74 , in the present group, have the same ovolo as a bowl with the same stamp found at Neidenbach and now in the Provinzialmuseum at Trier (no. I0535a); the ovolo of no. 65 with the stamp ofmo is identical with that of a bowl of the same potter at Nijmegen; and the two bowls of Mercator figured by $\mathrm{Knorr}^{5}$ have the same ovolo as a stamped bowl of the same potter from Silchester. A difficulty, however, arises from the fact that many ovolos, while not identical, differ so slightly that they can only be distinguished in a rubbing, a cast or a drawing of extreme accuracy. Thus the ovolo of no. 67 differs only from that of Mommo, no. 54, in being slightly smaller.

" THE POTTER OF THE LARGE ROSETTE."

(Plates VII-X).

In the present case it has been possible by this means to form two groups, one of nineteen bowls, the other of ten, the separate pieces of which can be attributed with some probability to the

\footnotetext{
${ }^{1}$ Knorr, Rottweil, rgiz, Taf. i, 15.

${ }^{2}$ cf. Hahnle, Die Relief-Kelcbe aus Haltern in the Mitt. d. Altertumskom. für Westfalen, vi, 1912.

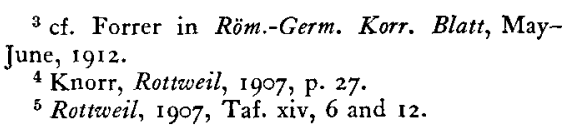


same potter. The first group, nos. 39 to 54 and 83 , are all distinguished by a finely-moulded ovolo, whose tongue ends in a large rosette. In addition to the ovolo the decoration of many of the bowls is strikingly similar. Not only details of design, but whole friezes, are repeated in a manner as nearly as possible identical. Thus the whole decoration of nos. 43 and $43 \mathrm{a}$ is identical, except that the group of the dog chasing the rabbit in the upper frieze occurs eight times in the former and only five times in the latter. The lower frieze of these bowls is repeated exactly on no. 45 , whose upper frieze is identical with that of 44 . The upper frieze of no. $4^{I^{1}}$ is the same as that of no. 43 , while its lower frieze repeats that of nos. 42 and $42 a$, which were made in the same mould. The narrow wreath which divides the friezes or is placed at the top or bottom of the decoration occurs in the same form on twelve bowls. The rinceaux of nos. 39 and 39a, $44,46,47$ and 52 , have common elements in details and arrangement. The various similarities of the different bowls of this group are given in detail in the description of the bowls below. 'The workmanship is generally good, the impressions being almost always sharp and clear. The mould, however, from which nos. 39 and 39a were made is an exception, one side being badly blurred while the other is perfectly sharp and good. The arrangement of the designs, however, is often faulty. In the mould of 42 and $42 a$ one of the spaces of the rinceau is smaller than the others, and the design which should fill it has had to be altered for lack of room. Similarly the size of the metopes in the frieze often differs considerably. Thus, in the upper frieze of no. 49, the number of columns of arrowheads varies between six and fourteen, and in one of the groups the hare which the dog should be chasing has been left to the imagination for lack of space to include it.

It seems clear, from the large number of irregularities, especially in rinceaux on bowls of this period, that the design was drawn freehand on the inner surface of the mould without the use of dividers to ensure exact spacing. The accuracy of the concentric circles which form medallions, on the other hand, points clearly to the use of compasses, and cases have been observed where the actual marks of their use are still visible.

Three other bowls, nos. 37,38 and $38 \mathrm{a}$, the two last having exactly the same design, have resemblances with this group so striking that one is tempted to include them in spite of the fact that their ovolo is different. The details of their similarity are given in the description of the separate bowls below. A bowl found at Richborough $^{2}$ has a decoration containing almost all the elements of no. 38 , the lozenge-shaped leaves and both the wreaths, and has,

\footnotetext{
1 The drawing of no. $4 \mathrm{I}$ is inaccurate; the hinder animal should be the same $\operatorname{dog}$ as appears on no. 43 .
}

${ }^{2}$ C. Roach Smith, The Antiquities of Ricbborough, etc. pl. iii, I. 
moreover, the ovolo with tassel ending in a large rosette which characterises this group. The same details occur also on a bowl from the cellar-find at Bregenz, no. 16 , with the same ovolo. ${ }^{1}$ Including these three bowls, which if not made by the same potter as the others, must be the work of one in close touch with him, the group consists of twenty-two bowls, of which nineteen have decoration of the earliest class in zones, three (nos. 50, 53 and 83) in metopes, but only seven, representing five different designs, have a purely ornamental pattern. Most of the bowls, that is, belong to a stage intermediate between Déchelette's first and second class. The three bowls with metopes have the most advanced designs of any in the hoard. All have divided metopes, and the decoration of no. 50 has been referred to above (p. 35) as nearly approaching the type of the Domitian-'Trajan period. It is a mark of the extreme rapidity with which the transition to the mixed style was progressing that bowls so different in design as nos. 47 and 50 should issue from the workshop of the same potter and at the same time.

It is not possible to assign this group with certainty to any known potter, bowls of form 37 with this ovolo, bearing a stamp, have been sought in vain, and it is most unfortunate that the stamp on no. 45, which might have solved the problem, proved quite illegible. A bowl of form 30 , however, with the stamp pavlLi among the decoration, and having an ovolo similar to this one, but unfortunately badly blurred, has been found at Rottweil. ${ }^{2}$ On the ground of this bowl, Knorr attributes to Paullus bowls of form $30,{ }^{3}$ and form $37,{ }^{4}$ which all have parallels with the present group other than the ovolo. Moreover, a bowl of form 29 with the stamp of Paullus, which bears a detail occurring on some of the bowls of this group, has been found at Pompeii. ${ }^{5}$ On the other hand, the ovolo of the stamped Rottweil piece is badly blurred, and the decoration is very different from any of our Pompeian group. It would be rash, therefore, to attribute the group definitely to Paullus.

The wares of this potter, whether Paullus or another, are widely distributed. A small fragment with the typical ovolo and a wreath formed of a three-leafed ornament, which occurs on no. 38 , etc. was found at Ostia. Two bowls occur at Nijmegen, the one closely resembling no. 44, the other with types found on nos, $4 \circ, 42$ and 49. A fragment in the British Museum ${ }^{6}$ is probably identical with 42 , or at least closely resembles it. A small fragment from Bitterne, near Southampton, with a rinceau resembling that of $5^{2}$, is probably to be attributed to this potter also. A piece was found among

\footnotetext{
1 Fabrbucb für Altertumskunde, vi, 19ı2, p. г78, Taf. iii.

${ }^{2}$ Knorr, Rottweil, 1907, xiv, 7 .

${ }^{3}$ Rottzueil, I9I2, xvi, 1,14 and 15.
}

${ }^{4}$ ibid. xix, I, 2, and xx, 2.
${ }^{5}$ Déchelette, i, p. 97, fig. 66.
${ }^{6}$ Cat. p. 130, fig. 130, M. 480. 
the Plicque collection from Lezoux, now in Saint-Germain museum, which has the same ovolo and the commonly-used wreath. Its glaze is noted as being darker and harder than that of most of the pieces in that collection. Examples from Rottweil are referred to above, and another with the ovolo and decoration of this type from the same site is published in Fundberichte aus Scbwaben, xviii, I9IO, Taf. v, fig. Io. The bowl from Bregenz already mentioned was associated with bowls most of which must be assigned to a date ten or twenty years later than the destruction of Pompeii, but the bowl differs in decoration from the majority of the pieces found with it, and should be classed with the few pieces, including a fragment of form 29, with the stamp of Germanus, which belong to an earlier period. There is, therefore, no evidence for dating this potter later than 79, except the bowl with the stamp of Paullus, which probably belongs to the reign of Domitian; but it has been shown that this cannot safely be included among the works of our potter.

\section{MOMMO (?) \\ (PLATES XI-XIII).}

The common origin of the bowls of the second group, comprising ten pieces, nos. 54 to 63 , is less well attested than that of the previous group. The similarities between the various designs is less striking and the evidence of the ovolo less conclusive. It is, however, probable that they should all be attributed to the potter Mommo. No. 54 has the stamp мом in cursive letters in relief under the decoration, and an ovolo with a tassel ending in three prongs. It must be admitted that such a tassel is of common occurrence at this period, and was certainly used by more than one potter, but the ovolos of the nine bowls, nos. 55 to 63 , not only have the same tassel but agree perfectly in size with that of no. 54. The evidence of the bowls of form 29 with the stamp of Mommo is sufficient to prove that he possessed a large number of poingons, and used them to form designs of very varying character, so that it was not perhaps to be expected that the common elements would be so numerous as in the preceding group. Eight of these ten bowls have decoration in metopes, a fact which agrees well with their attribution to Mommo, whose bowls of form 29 have been shown to have more advanced types of decoration than those, for example, of Vitalis. Among the similarities of decoration may be cited the use of dart-shaped leaves on nos. 55, 58, 59 and 6I, and commonly on the bowls of Mommo of form 29. So, too, the wreaths of nos. 55, 56 and 57. Other examples will be found in the separate descriptions below. Many 
of the types and arrangements of decoration found on these ten bowis are also present on bowls with the same ovolo in the British Museum. ${ }^{1}$ No. 59 has already been referred to as probably bearing the remains of the stamp of Mommo, which occurs on 54. It is possible that no. 82 also belongs to this group. Its ovolo has a tassel ending in three prongs, and the design has some similarities in arrangement with other bowls of the group, but unfortunately, owing to its subject, it was not available for close examination.

MEMOR.

(PLATE XIV).

Two bowls, nos. 73 and 74, bear below the decoration the name of Memor incised upside down in cursive letters in the mould. The designs of the two bowls are strikingly similar both in details and in arrangement. The moulds of both are sharp and well finished. These bowls have few parallels with the others of the hoard but are shown through the bowl at Trier, referred to above (p. 36), to have some connexion with the potter of the preceding group. The erotic scene of no. 83, for example, is repeated on the bowl at Trier. Stamps of Memor are fairly commonly found on plain ware, but no reference has been found to other decorated bowls with his stamp. The bowl from Pompeii, figured by Déchelette, ${ }^{1}$ has considerable resemblance to nos. 73 and 74 and may well be a work of this potter. The ovolo, the upper part of which is destroyed by the rim, is blurred in the mould, but seems at least to be very similar to that of Memor, and the ornament inclosed in the garland is identical with that in the medallion of no. 73. The stamp of Memor occurs in the Flavian fort at Hofheim and in both strata at Wiesbaden, so that he began to work under Nero, but there is no evidence to prove his beginning earlier than the seventh decade of the century. He is found at Rottweil on form 18 , in London on forms 18 and 27, and at Silchester on form 27. None of his stamps, however, seem to have been found, so far, on sites whose occupation began under Domitian, so that the evidence only permits us to assign this activity to the years 6o-80, though it may well have continued ten or even twenty years longer. The bowl no. 64 has an ovolo closely resembling that of Memor, and it is possible that he may have been its maker, but the identity of the two ovolos is not certain and the decorations have few parallels. No. 66 is, however, very similar to it, having the same wreath under the ovolo and the same dolphin in alternate metopes. But the ovolo of this bowl does not resemble that of 64 , but is identical with the ovolo of 65 with the stamp ofmo. To this bowl, no. 66 has other close similarities, and it may perhaps be attributed to the same potter.

1 vol. i, p. $9^{8}$, fig. 67 . 


\section{MO(DESTUS ?) \\ (PLATE XIII).}

Of the potters of this period whose names begin with MoMommo, Modestus, Montanus and Monticus or Mont. Cl.-it seems hard to decide which has the right to claim the stamp ofmo of no. 65 . Déchelette ${ }^{1}$ attributes it to Mommo, who is proved by the present find to be connected with the potter who used it, but the difference between the ovolos of the two bowls, nos. 54 and 65, which bear respectively the stamp of Mommo and ofmo, is a strong objection to the attribution. Ritterling ${ }^{2}$ takes the stamp to be that of Modestus, but this potter is not represented among the other bowls of the hoard, and, as far as can be judged, his types of decoration are not very closely allied to those of the potters who form this group. It seems clear that the various forms of the stamp Montanus given in C.I.L. xiii, I0010, 1382, belong to more than one potter. ${ }^{3}$ The two stamps. in the British Museum ${ }^{4}$ are assigned respectively to potters of Gallia Belgica and south Gaul. That one of the potters of this name was active under Vespasian and Domitian is shown by the occurrence of the stamp at Rottweil, ${ }^{5}$ and among the early pottery found at Tullie-house, Carlisle, ${ }^{6}$ but in the absence of decorated bowls with his stamp, the claim of this potter to the stamp ofmo must be left undecided. The claim of Monticus or Mont. Cl., who is shown by his appearance elsewhere to belong to this period, depends in part on the attribution to him of the stamp of no. 33, but in any case the meagre decoration of that bowl resembles neither the design of no. 65 nor of a fragment at Nijmegen made by the same potter. The present evidence is insufficient, then, to admit of certainty in the attribution of this stamp, nor is it possible to discuss the distribution of his wares, since they are included among those of the above-mentioned potters without distinction.

\section{RUFINUS (?).}

The two bowls, nos. 75 and 77 , have the same ovolo and other similarities. The narrow wreath of no. 75 is formed of the same V-shaped leaf as occurs on no. 36, which bears the stamp of Rufinus. This latter bowl has an upper trieze identical with that of no. 77 , the arrangement of the lower friezes of the two bowls is the same, and on each the grass plant is formed from the same poincon, thrice repeated. So near an approach to identity in the decoration of these bowls makes it probable that nos. 75 and 77 are the work of Rufinus.

\footnotetext{
1 vol. i, p. 289 .

${ }^{2}$ Hofbeim, 1913, p. 246.

3. cf. Ritterling, Hofbein; Ig 13, p. 240 and p. 246 , where the statistics of the finds suggest a much earlier date for one of the potters.
}

\footnotetext{
${ }^{4}$ Cat. nos. M. 96 and M. 83 I.

${ }^{5}$ Knorr, Rottweil, 1907, p. 64 .

${ }^{\theta}$ Bushe-Fox, p. 30 .
} 


\section{UNIDENTIFIED.}

Nos. 76 and 80 have resemblances which suggest that they should be classed together as the work of one potter. The ovolos are the same and the arrangements and details of the cruciform ornaments are very similar.

The remaining bowls have, in most cases, parallels with those already discussed, and these are noted in the detailed descriptions below, but they are not such as to enable the bowls to be assigned with probability to any particular potter or to any of the groups distinguished within the hoard.

In the detailed descriptions which follow, parallels have been sought rather within the hoard than from finds made elsewhere. Their purpose is, by illustrating the connexion which exists between the types of decoration used in the various groups, to confirm the hypothesis suggested. by the circumstances of the discovery that the hoard is composed of bowls strictly contemporary and made by potters working in association; and, as a corollary to this, to show the extent and nature of the material at the disposal of such a group of potters. The references for the various types are, when possible, given to the collection in the second volume of Déchelette's work, or failing this to the various publications of Knorr.

\section{GROUP I. BOWLS OF FORM 29 WITH STAMP OF MOMMO}

(Plates II-Vi, NOS. I-23).

I. I 3 OI6, I25/1882. Not. Scav. в. $5 \mathrm{I}$, form 29, diam. $23 \mathrm{~cm}$. stamp ofN"in!inv. ${ }^{1}$

Upper frieze; divided into metopes by zigzag lines. The arrangement from left to right is, (I) dog as on no. I7, like Déch. 924, but larger ; (2) arrow-heads ; (3) goose (?) like Déch. 1008, but smaller; (4) arrow-heads; (5) bird as on 81, like Déch. 1033, but smaller ; (6) arrow-heads ; (7) repeats (I); (8) arrow-heads; (9) repeats (5); (IO) arrow-heads; (II) repeats (3); (I 2) arrow-heads; (I3) repeats (5). Both the birds seem to be taken from the material of pre-Flavian potters ; the goose (?) occurs on a bowl of Albinus, the other on a bowl of form I I with the stamp Volus(enus), but in each case the earlier example is larger. Lower frieze; godroons slightly twisted to the left.

2. I 13008, I17/1882. Not. Scav. в. 43, form 29, diam. $24 \cdot 8 \mathrm{~cm}$. stamp ofMoN. The lower frieze also contains a stamp mom inverted.

Upper frieze; metopes divided by three vertical zigzag lines and

1 The first two numbers are taken from the bowls. The reference to Notizie degli Scavi is to the description of the several bowls, (A) to the first group ( $188 \mathrm{r}, \mathrm{p} .300$, f.) and (B) (1882, p. $275, f$.). 
containing alternately (I) two rows of $\mathrm{V}$-shaped leaves as on no. I 5, but without the line between them; (2) a group of a dog to right and a panther (?) as on no. 6I. Lower frieze ; a narrow wreath formed of a four-leafed ornament ( $I$ on fig. 4) as on no. 57. Below, metopes divided by upright zigzag lines, varying in number from two to six, and containing alternately (I) a double circle containing a dog (Knorr, Rottweil, 1912, viii, 2) with a corner curl on either side ending in a catkin, as on no. 17 ; the stamp occurs once under this medallion; (2) group of two lions face to face. The one on the left is like Knorr, Rottweil, rgI2, xi, I ; the other occurs on no. 79 and probably on no. I5. Under this group four V-shaped leaves.

3. II29I0. Not. Scav. A. I9, form 29, diam. I9 cm. stamp ofMoм. Upper frieze; metopes divided by zigzag lines ending in rosettes of seven points, containing alternately (I) dog, as on no. 7 , chasing rabbit as on nos. 5 and 33 , and (2) diagonal lines and arrowheads. Lower frieze; narrow wreath formed of three-leafed ornament. Below, metopes, (r) medallion formed of two concentric circles containing a bird to right (Knorr, Rottweil, I9I 2, iii, $\mathrm{I}$ ); (2) cruciform ornament. The three-leafed ornament ( $\mathrm{k}$ on fig. 4) which fills the four spaces as on nos. $13,18,29,66$; (3) medallion as (I) with same bird to left ; (4) repeats (2): the metopes (I) and (3) have corner curls irregularly placed, sometimes four, sometimes three, one or none. In one case two consecutive medallions contain the bird to the left.

4. II 2922. Not. Scav. A. 3I, form 29, diam. $15 \mathrm{~cm}$. stamp OFNIIIIN.

Upper frieze; festoons containing small dog alternately left and right. The tassel ends in a double leaf ( $P$ on fig. 4 ), as on nos. 19 and 24 , which is repeated as a continuous wreath in the lower frieze. Below is a series of S-ornaments.

The dog seems to be a copy of that occurring on nos. I and I7, but it is only half the size.

5. $113005,114 / 1882$. Not. Scav. B. 39, form 29, diam. I6. $4 \mathrm{~cm}$. stamp ofMow, burnt black.

Upper frieze; metopes divided by zigzag lines ending in rosettes of seven points, (I) dog to right, as on no. 8; (2) arrow-heads; (3) rabbit, as on nos. 3,33 and 35 ; (4) arrow-heads. Lower frieze; metopes, (I) medallion with three corner curls ending in dart-shaped leaves and containing a cupid (Déch. 274); (2) cruciform ornament formed of dart-shaped leaves which occur commonly, especially on the bowls of Mommo, and arrow-heads, cf. no. 3I ; (3) like (I), but the medallion contains a figure seated on a rock (Déch. 537); (4) repeats (2). 
6. I I 2996, I 05/1882. Not. Scav. в. 3 I, form 29, diam. I8.4 cm. stamp OFMON.

Upper frieze; metopes divided by zigzag lines, (I) small arrowheads; (2) sitting rabbit (cf. Déch. 95I); (3) large arrow-heads; (4) dog to left, as on no. 5 I (Knorr, Rottweil, I9I2, vi, I I). Lower frieze; wreath formed of broad shell-like leaves (Knorr, Rottweil, I9I 2, i, II). Below, metopes divided by zigzag lines varying from four to six, and containing alternately a lion (Knorr, Rottweil, I9I2, xiii, 2) and a boar to left, like those on no. 53 but smaller. Below, a narrow wreath formed of the large arrow-heads used in the upper frieze. They occur similarly placed on no. 35 .

7. I I 2925, 34/1882. Not. Scav. A. 34, form 29, diam. I7*4 cm. stamp oFMON, burnt black.

Upper frieze; metopes divided by zigzag lines (I) arrow-heads placed vertically; (2) dog to right, as on no. 3; (3) arrow-heads placed horizontally; (4) rabbit, as on no. I8. Lower frieze; godroons, as on two other bowls from Pompeii stamped VIRHV and OFSILVANI.

8. I I 2984, 93/1882. Not. Scav. в. I9, form 29, diam. I6 cm. stamp OFMON.

Upper frieze ; metopes divided by zigzag lines ending in rosettes, (I) arrow-heads; (2) dog to right, as on no. 5. Lower frieze; metopes, (I) cupid, as on nos. 60 and 62 (Déch. 280); (2) four conventional flowers on upright zigzag stems.

9. I I300I, I IO/I882. Not. Scav. в. 36 , form 29 , diam. $21 \cdot 2 \mathrm{~cm}$. stamp ofNmi JN, mottled red and black.

Upper frieze; metopes divided by zigzag lines ending in rosettes, (I) dog to right, as on nos. $3 \mathrm{I}, 40,42,49,6 \mathrm{I}, 83$; (2) arrow-heads; (3) speckled hare, as on nos. 3I, 40, 42, 48, 49, 5I, 6I, 83. Lower frieze; metopes, (I) cruciform ornament almost identical with no. I4; the ornament in the lower space alone is different; (2) an ornament in a medallion resembling closely the ornament in the medallion on no. I4; (3) arrow-heads. The arrangement of the metopes is irregular.

Io. I I 2966. Not. Scav. B. I, form 29, diam. $23 \mathrm{~cm}$. stamp oFA min.

Upper frieze ; metopes divided by zigzag lines ending in rosettes, (1) dog to right (Knorr, Rottweil, I912, xxiii, 8) ; (2) circle containing a four-petalled flower, as on no. I4; (3) an animal to left, as on nos. 32 and 76 . 'The metopes (I) and (3) are placed irregularly. Lower frieze; metopes, (I) medallion containing an eagle, as on nos. I I, 55 and 72 , like Déch. 982 but smaller; (2) arrow-heads and diagonal line; (3) repeats ( 1 ); (4) cruciform ornament formed of 
poppy-heads ( $\mathrm{T}$ on fig. 4) and dart-shaped leaves, which occur commonly on these bowls, sceptre-shaped leaves (R on fig. 4 ), as on nos. 35 and 36 , and arrow-heads. Owing to inaccurate spacing in the mould, room is lacking in one place for the arrow-heads and lines, and a figure, probably Knorr, Rottweil, I9I 2, xv, I and 2, is inserted instead.

II. Il3013. Not. Scav. B. 48 , form 29, diam. $23 \mathrm{~cm}$. stamp OFN:I:IM.

Upper frieze; metopes divided by zigzag lines ending in rosettes and containing alternately arrow-heads and groups of festoons, with beaded tassel ending in four-leaved ornament ( $\mathrm{L}$ on fig. 4), as on no. 28 , and enclosing a spiral ending in a rosette. In three groups there are four festoons, in the fourth only three. Lower frieze; metopes, (I) cruciform ornament formed of poppy-heads ( $\mathrm{T}$ on fig. 4) and dart-shaped leaves (cf. no. Io); (2) a medallion containing an eagle, as on nos. IO, 55 and 72 . In one place arrow-heads and diagonal lines are substituted for the cruciform ornament. Corner curls, sometimes two, sometimes three, fill the angles of metope (2).

I2. II3OI 5, I24/1882. Not. Scav. B. 50, form 29, diam. $23.6 \mathrm{~cm}$. stamp oFMllilW.

Upper frieze; metopes divided by zigzag lines, (I) boar to left : Déch. 837, as on no. 49; (2) arrow-heads ; (3) dog, like Déch. 926, but smaller, as on no. 49 (Knorr, Rottweil, I9I2, xi, I, where the whole frieze is very similar). Three small ornaments formed of two concentric circles are placed under each animal. The lower frieze has not been copied. The description in the Notizie, "four squares each with two dogs which pursue a hare and rabbits," may refer to a design like Knorr, Rottweil, r907, iii, I.

I3. I I 2995, I04/1882. Not. Scav. в. 30, form 22, diam. I8. $8 \mathrm{~cm}$. stamp of:ilo:W.

Upper frieze; metopes divided by zigzag lines, (I) a small lion (Knorr, Rottweil, I912, xvi, I I), which occurs on stamped bowls of Sasmonos and L. Cosius, and is taken from the material of the earlier potter Masclus (cf. Knorr, Rottweil, 1907, xiii, 2) ; (2) arrowheads; (3) small bear, as on no. 15 . 'This also is a copy of the similar animal on the bowl of Masclus. Lower frieze ; metopes, (I) cruciform ornament formed of a three-leafed ornament, too blurred to be identified, in the upper space, in the side spaces tendrils ending in dart-shaped leaves, and in the lower space a three-leafed ornament (E on fig. 4), as on nos. $29,48,64,65,66,73$ and $80 ;(2)$ a notched circle enclosing a cruciform ornament composed of the three-leafed pattern ( $\mathrm{k}$ on fig. 4), which occurs on nos. $3,18,29$ and 66. The upper angles of this metope contain spirals ending in a rosette. 
Through an error in spacing, one of the cruciform ornaments of metope (I) is only half the normal width.

I4. I I3009. Not. Scav. в. 44, form 29, diam. $24 \cdot 8 \mathrm{~cm}$. stamp OFMON.

Upper frieze; rinceau. Above the central stem a spiral ending in a rosette and two leaves of which the smaller (Q on fig. 4 ) occurs on nos. 9, 73 and 76 . Below the stem a circle enclosing a flower of four petals, as on no. Io. Lower frieze; metopes, (I) divided by zigzag line ending in rosettes. Above, a lion to right as on nos. $36,50,75$ and 77 , below, arrow-heads; (2) cruciform; in the upper space a three-leafed ornament (c on fig. 4) and two dart-shaped leaves, in the side spaces dart-shaped leaves, below, same three-leafed ornament; (3) conventional palmette in double circle, with two rosettes above. With metopes (2) and (3) compare no. 9 above.

I 5. I I 2976. Not. Scav. в. I I, form 29, diam. 2 I cm. stamp OFMOM.

The lower frieze also contains the stamp ofmom reversed among the decoration.

Upper frieze; metopes divided by zigzag lines, (I) two rows of $\mathrm{V}$-shaped leaves as on no. 2, separated by a zigzag line ; (2) rinceau starting from and ending in a rosette at the end of a zigzag line. The two upper spaces are filled by a spiral ending in a small rosette and a stem ending in a flower formed of 6 dots (o on fig. 4), as on nos. 26 and 30 , and a bowl with the stamp of Vitalis at Nijmegen. Lower frieze; free style and medallions, (I) double circle, the outer notched as on no. 2, containing a dog (Déch. 922); (2) lion chasing a deer to the left. The lion is blurred, but is probably as on nos. 2 and 79. The deer is found in Knorr, Rottweil, 1907, vi, 3, and vii, 1 , with stamp of Germanus. The stamp ofMOM is placed under two adjacent examples of this group; (3) medallion as (I), containing small bear as on no. I3. The blank spaces of the design are filled by small notched circles. Below, a wreath formed of the leaves used in the upper frieze.

16. I I2927, 36/1882. Not. Scav. A. 35, form 29, diam. $157 \mathrm{~cm}$. stamp ofMow, burnt black.

Upper frieze; rinceau, of which the upper part has been obliterated in setting on the rim. A spiral ending in a rosette and a brushshaped ornament of four leaves spring from the central stem. On each side of the spiral a small rosette. Lower frieze; rinceau. Above the central stem two leaves, one with serrated edge, the other formed of five lobes. Below the stem a conventional palm flanked by stalks ending in the small leaf of the upper spaces. Two of the upper spaces are irregular; in one is another conventional palm 
with spirals springing from the head and two large rosettes above; in the other, for the small leaf is substituted a larger one like that on nos. 43 and 45 .

I7. I 1 2994, 103/1882. Not. Scav. в. 29, form 29, diam. $20 \cdot 8 \mathrm{~cm}$. stamp oFM $\%$ iN.

Upper frieze; rinceau, above the central stem a spiral ending in a rosette and a three-leafed ornament ( $\mathrm{F}$ on fig. 4 ), as on 34 , below the stem the ornament formed of three poppy-heads ( $T$ on fig. 4), which occurs frequently, in this case inverted. Lower frieze; rinceau, above the central stem three leaves, the middle one as on no. 2; with the others, cf. Knorr, Rottweil, I9I2, iv, 4. Below it alternately a winged horse and a dog (Déch. 924) over two rows of arrow-heads. The lower frieze is badly impressed and the details are hardly discernible.

I8. I I 2978, 87/1882. Not. Scav. в. I3, form 29, diam. 17'3 cm. stamp ofMON.

Upper frieze; continuous wreath formed of three-leafed ornament (A on fig. 4), as on nos. 24 and 68, with rosettes on both sides. Lower frieze; metopes, (I) cruciform, in the upper space the same ornament as forms the wreath above, in the side spaces dart-shaped leaves and below three-leafed ornament ( $\mathrm{k}$ on fig. 4), as on nos. 3 , I3, 29 and 66 ; (2) medallion as on no. I9, containing a rabbit as on no. 7; (3) repeats (I) ; (4) medallion as (2), enclosing dog like Déch. 939. In one case the rabbit is placed in two consecutive medallions. Metopes (2) and (4) have corner curls ending in dartshaped leaves.

I9. I I 2982, 91/1882. Not. Scav. в. 17, form 29, diam. $17.5 \mathrm{~cm}$. stamp orm:lin.

Upper frieze; festoons, each a wreath with V-shaped notches enclosing a spiral ending in a rosette to left and right alternately. The tassel ends in a double leaf ( $P$ on fig. 4 ), as on nos. 4 and 24 . Lower frieze; metopes, containing alternately arrow-heads and a medallion as on no. I8, enclosing a bird to the left with head turned back like that on nos. 44 and 45 . On each side of the medallion a corner curl ending in a pointed leaf.

20. 112999, 108/1882. Not. Scav. в. 34, form 29, diam. 16.4 cm. stamp OFMON.

Upper frieze; a series of S-pattern with curled ends. These occur facing in pairs on a much earlier bowl of form 29 at Wiesbaden. Lower frieze; rinceau, above the central stem two leaves with wavy edges, above them three rosettes, below the stem, imbrication formed of large rosettes overlapping. The lower frieze is much blurred and the details are uncertain. 
21. I I2924. Not. Scav. A. 23, form 29, diam. I9 cm. stamp oFMON, burnt black.

Upper frieze; rinceau consisting of single bud (s on fig. 4 ) as on no. 29, and a spiral ending in a rosette. The junctions of the stems are covered by a small two-leafed ornament (see above, p. 36). Lower frieze ; three wreaths, the uppermost enclosed within rows of dots.

22. I I2892. Not. Scav. A. I, form 29, diam. $25.5 \mathrm{~cm}$. stamp OF:I: OM.

Upper frieze ; rinceau, above the central stem a leaf and a spiral ending in a rosette, a smaller spiral issues from the points of junction, below the stem arrow-heads. Lower frieze; narrow godroons similar to those of no. 69, much blurred, narrow wreath below.

23. I I3002, I I I/I882. Not. Scav. в. 37, form 29, diam. 2 I cm. stamp OFN:HOW.

Upper frieze ; festoons, containing each two heart-shaped leaves as Knorr, Rottweil, I9I2, viii, 7, with their stems crossed. The festoons hang from a bar formed of five rings, the tassel ends in an almost circular bud. Lower frieze; a series of upright zigzag stalks ending in the bud of the upper frieze. The lower part of the stalks are blurred in the mould.

GROUP II. BOWLS OF FORM 29 BY VARIOUS POTTERS (NOS. 24-36).

24. I I 2980, 89/1882. Not. Scav. в. I 5, form 29 , diam. I7' I cm. stamp ofscrn (? = Secundus).

Upper frieze; rinceau, on either side of the central stem a small spiral, a large spiral ending in a rosette and a stalk ending in a double leaf ( $P$ on fig. 4 ), as on nos. 4 and 19 . At one point the rinceau is broken and a three-leafed ornament inserted. Lower frieze; festoons notched on the outer side, each containing the conventional dartornament (cf. nos. 57 and 63). The tassel ends in a three-leafed ornament (A on fig. 4), as on nos. 18 and 68.

25. I I30I7. Not. Scav. B. 52, form 29, diam. I4.7 cm. stamp illegible.

Upper frieze; rinceau, on either side of the stem a spiral and another stem ending in rosettes. Lower frieze; godroons much blurred. The rim is carelessly set on, and has destroyed the top of the rinceau.

26. I 12977. Not. Scav. в. I2, form 29, diam. I8· I cm. stamp OFVITA.4

Upper frieze; wreath formed of three flowers composed of six dots. Lower frieze, godroons as on no. 29. 
27. II 3010, I19/1882. Not. Scav. в. 45, form 29, diam. $25 \mathrm{~cm}$. stamp as on no. 26.

Upper frieze ; festoons as on no. 29, containing a spiral ending in a rosette and a stem ending in a three-leafed ornament (Knorr, Rottweil, I9I 2, v, I). The tassel ends in a large two-leafed ornament. Lower frieze; rinceau, on either side of the central stem a small sceptre-shaped leaf (Knorr, Rottweil, I9I2, iv, II), two angular leaves (Knorr, Rottweil, I9I 2, ii, 5), as on no. 21, with a three-leafed ornament between them.

28. I I 2974, 83/1882. Not. Scav. в. 9, form 29, diam. $20^{\circ} 5 \mathrm{~cm}$. stamp as on no. 26 .

Upper frieze; festoons formed by series of small v's (Knorr, Rottweil, I9I2, v, I9) with beaded tassel ending in four-leafed ornament (L on fig. 4), as on no. II. Each festoon contains a large rosette of fifteen points with a small one in its centre. Lower frieze; trellis of zigzag lines with one or two small rosettes in each space.

29. I I2971, 80/1882. Not. Scav. в. 6, form 29, diam. $24 \mathrm{~cm}$. stamp as on no. 26.

Upper frieze; festoons with beaded tassel ending in three-leafed ornament ( $\mathrm{k}$ on fig. 4), as on nos. 3, I3, 18 and 66. The festoons each contain a spiral ending in a rosette and a bud (s on fig. 4), as on no. 21. Lower frieze; godroons as on no. 26. Below, a wreath formed of three-leafed ornament (E on fig. 4), as on nos. 3, 48, 64, $65,66,73$ and 80 . The close similarity between this bowl and those of Knorr, Rottweil, I9I2, Taf. I, justifies their attribution to the group of potters of whom Vitalis was one, and Taf. i, 2, might well be the work of that potter.

30. II 2973, 82/1882. Not. Scav. в. 8, form 29, diam. 22. I cm. stamp as on no. 26.

Upper frieze ; two rows of shell-like leaves (cf. Knorr, Rottweil, I907, ii, I) with stamp sever, divided by a zigzag line. Lower frieze; two bands with the same decoration. A cruciform ornament of which the upper space is filled by two dart-shaped leaves flanking a flower of six dots (o on fig. 4), as on nos. 15 and 26. The side spaces contain small feathery leaves as on bowls of form 29 with stamps OFCRESTIO and OFPRIMI, from Silchester. The lower space has dart-shaped leaves. This design alternates with series of five upright stems linked together at the bottom in threes by semicircles and ending alternately in diamond-shaped leaves and the flower of the upper space of the cruciform. In one case there are three instead of five stems, and once the arrangement of the leaves and flowers is altered.

31. I I 3003. Not. Scav. в. 38, form 29, diam. $19 \mathrm{~cm}$. stamp MANDVIIM. 
Upper frieze; metopes divided by zigzag lines, (I) dog, as on nos. $9,40,42,49,61$ and 83 ; (2) arrow-heads ; (3) speckled hare, as on nos. 9, 40, 42, 48, 49, 5I, 6I and 83. Lower frieze; metopes, (I) palmette on zigzag stem flanked by long stalks ending in dart-shaped leaves; (2) cruciform: in the upper space and side, dart-shaped leaves, below a four-leafed ornament like that of 5 ; (3) male figure moving to right with cloak flowing out behind the right shoulder, as on nos. $5^{8}$ and 82 .

32. I I 2926, 35/1882. Not. Scav. A. 36, form 29, diam. $17^{\circ} 4 \mathrm{~cm}$. stamp ANDVI 1 M, mottled red and black.

Upper frieze; metopes divided by zigzag lines, (I) animal (? deer) to left, as on nos. 10 and 76 ; (2) imbrication formed of leaves; (3) winged horse as on nos. 64,76 and 80 . Lower frieze; metopes, (I) combat of gladiators; (2) medallion containing the bird of nos. $19,44,45$. Both metopes have two corner curls ending in dartshaped leaves.

33. I I 3000, I09/1882. Not. Scav. B. 35, form 29, diam. I4.2 cm. stamp ofMOmili (see above p. 34).

Upper frieze; metopes irregularly arranged, (I) group of small dog as on no. 35 , chasing rabbit, as on nos. 3,5 and $35 ;(2)$ a wreath formed of a three-leafed ornament starting from a conventional plant on the left ; (3) small dog to right, like Déch. 924, but smaller ; (4) repeats (2); (5) dog of group (I); (6) repeats (2); (7) rabbit of group (I); (8) repeats (2); (9) repeats (7); (I0) repeats (2). Lower frieze; two bands, the upper a continuous wreath as on the upper frieze, the lower a series of $V$-shaped ornaments.

34. I I 3012, I21/1882. Not. Scav. в. 47 , form 29, diam. $24^{\cdot} 6 \mathrm{~cm}$. stamp OFPARICI : also traces of another stamp under the decoration (see above, p. 30).

Upper frieze; rinceau (cf. Knorr, Rottweil, I9I2, ix, I), on either side of the central stem a small spiral, a larger spiral ending in a rosette and a stem ending in a three-leafed ornament ( $F$ on fig. 4), as on no. I7. Lower frieze; rinceau, under the central stem, palmette ending above in three poppy-heads ( $\mathrm{T}$ on fig. 4 ), on each side a spiral ending in a rosette and below two long stems ending in a large leaf, as on Knorr, Rottweil, I9I2, iv, 10. 'The same general design occurs on nos. 9, I4 and I6. Above the central stem two angular leaves with another leaf between them; it is much blurred but is probably the leaf which flanks the palmette.

35. I I 2972, 8I/1882. Not. Scav. в. 7, form 29, diam. 2 I cm. stamp o:iRVFINI.

Upper frieze; metopes, (I) animal to right in festoon, the tassel 
of which ends in sceptre-shaped leaf ( $\mathrm{R}$ on fig. 4), as on nos. Io and 36 ; (2) diagonal lines and arrow-heads; (3) figure to left: Déch. 577 , as on nos. 54,74 ; (4) repeats $(2) ;(5)$ festoon as on (I), containing sitting hare as on nos. 6 and 55 ; (6) repeats (2); (7) repeats (3). Lower frieze; a narrow wreath formed of three-leafed ornament, as on no. 36 (Knorr, Rottweil, I9I 2, ix, 4). Below, a narrow band with animals, a dog as on no. 33, and a rabbit as on nos. 3,5 and 33 , separated by six sceptre-shaped ornaments, with a small rounded flower at the top. Under this a narrow wreath formed of large arrow-heads as on no. 6.

36. I I 2990, 99/1882. Not. Scav. в. 25, form 29, diam. $23.3 \mathrm{~cm}$. stamp OFRVFINI.

Upper frieze; rinceau, on either side of central stem a small spiral, a stem ending in the conventional dart-ornament, which occurs also on nos. $24,57,63$ and 71 , and a stem ending in a sceptreshaped leaf ( $\mathrm{R}$ on fig. 4) as on nos. Io and 35. This rinceau is repeated exactly on no. 77. Lower frieze; a wreath identical with that of no. 35. Below, a frieze of lions alternately left and right, separated by grass plants formed of the three-leafed ornament ( $\mathrm{J}$ on fig. 4), as on no. 77. Both lions occur on no. 50 and on Knorr, Rottweil, I9I 2, xi, I. The lion to the right is found also on nos. I4, 75 and 77. Under this a narrow wreath of $\mathrm{V}$-shaped leaves as on no. 75 .

GROUP III. BOWLS OF FORM 37 By THE " POTTER OF LARGE ROSETTE" (PLATES VII-X, NOS. 37-53).

37. I I 2979, 88/1882. Not. Scav. в. I4, form 37, diam. 16.3 cm. Small, finely moulded ovolo, with straight tongue attached to right of egg. The field is divided into two triezes by zigzag lines; below, the narrow wreath characteristic of this group. Upper frieze; rinceau, formed of a stem ending in a small three-leafed ornament ( $\mathrm{N}$ on fig. 4 ) and a spiral ending in a rosette, the blank spaces filled by tiny circles. The rinceau is identical with that of no. 52, except that it lacks the small spiral of the latter bowl. Lower frieze; S-pattern, as on nos. 39 and 47.

38. I I 2919, 28/1882. Not. Scav. A. 28, form 37, diam. $17 \mathrm{~cm}$. Ovolo as last. The field is divided by zigzag lines into two friezes separated by the characteristic wreath. Upper frieze; rinceau, the same design as the upper frieze of no. 37, except that every second lower space is filled by arrow-heads. Lower frieze; above, a series of spatula-shaped leaves; below, a wreath formed of the three-leafed ornament as on no. 46 . 
38a. I I 2920, 29/1882. Not. Scav. A. 29, form 37, diam. I6.5 cm.

A careful comparison of these two bowls nos. 38 and $38 \mathrm{a}$ failed to reveal any difference in the decoration and the difference in the diameter is remarkable. That it really exists is shown by the agreement of the writer's measurements with those given in the Notizie. It may be suggested that both were made in the same mould, and that the difference lies in the rims which were set on afterwards.

39. I I 2899, 8/1882. Not. Scav. A. 8, form 37, diam. 2 I cm.

Ovolo with tongue ending in large rosette. The field is divided into four zones by zigzag lines, (I) rinceau; above the central stem a round bud and a five-angled leaf as on no. 53, below the stem a similar bud, a spiral ending in a rosette and a smaller spiral (cf. no. 47); (2) wreath formed of $V$-shaped leaves; (3) rinceau with the same spirals as in (I) and in the upper spaces a rosette; (4) continuous band of S-pattern, as on nos. 37 and 47 .

39a. I I 2900, 9/1882. Not. Scav. A. 9, form 37, diam. 2 I cm. made in the same mould as 39.

40. I13007. Not. Scav. в. 42 , form 37, diam. $23.5 \mathrm{~cm}$.

Ovolo as last. The field is divided into four zones by zigzag lines: (1) the characteristic narrow wreath; (2) and (4) continuous band of oval ornaments as on no. 53 ; (3) metopes; alternately a group of a dog, as on nos. 9, 3I, 42, 49,61 and 83, chasing the hare of nos. 9, 3I, 42, 48, 49, 5I, 6I and 83, and arrow-heads. A bowl with the same ovolo and decoration almost identical has been found at Nijmegen.

41. II 2905, I4/1882. Not. Scav. A. I4, form 37, diam. I8.5 cm.

Ovolo as last. The field is divided into two friezes by the usual wreath. Upper frieze; divided by zigzag lines into metopes containing alternately arrow-heads and a group of a small dog chasing a rabbit, seven groups. Lower frieze; rinceau. In the spaces above the central stem is a three-leafed ornament flanked by leaves with wavy edges. A small duck is sometimes placed among the stems. Below the central stem the spaces are divided by zigzag lines ending in rosettes. Above the line are swans facing alternately left and right. Under the swan to the right the running dog, under the other the rabbit of the upper frieze. The upper frieze is repeated on no. 43, the lower on no. 42. Similar swans occur on nos. 56 and 67 .

42. II 2903, I2/1882. Not. Scav. A. I2, form 37, diam. I8.5 cm. Ovolo as last. The field is divided into two friezes by the usual 
wreath. The upper frieze is divided into metopes containing the large group of dog and hare as on 40 , and arrow-heads. The lower frieze is the same as that on no. 4I. Through a mistake in arrangement one of the lower spaces is only half the normal width and is filled by the small duck, which is found in the upper spaces, below this a small sitting rabbit.

42a. I I 2904, I3/1882. Not. Scav. A. I3, form 37, diam. I $8 \cdot 5 \mathrm{~cm}$. Made in the same mould as no. 42. The fragment in the British Museum (Cat. M. 480, p. I 30 , fig. I 30 ) is identical with this bowl as far as the two can be compared.

43. I I 2992. Not. Scav. B. 27, form 37, diam. $21 \mathrm{~cm}$.

Ovolo as last. The field is divided into two friezes by the usual wreath, which is also placed under the lower frieze. Upper frieze like no. 4I, but eight groups instead of seven. Lower frieze; rinceau, above the central stem a round bud flanked by leaves with serrated edges, below the stem medallions in groups of three. The middle one contains an eagle like Déch. 986, but much smaller; the other two, swans facing inwards, nine medallions in all. Here and there a small duck like Déch. IOI 7 is placed among the stems of the upper spaces. No. 45 has the same lower rinceau.

43a. I 12896, 4/1882. Not. Scav. A. 4, form 37, diam. $21 \mathrm{~cm}$. Bowl almost identical with last. The only difference lies in the number of groups of the dog and rabbit in the upper frieze. Here instead of eight there are five. The extra space is filled by placing the animals further apart and increasing the number of arrowheads in the alternate metopes.

44. I I 3004, I I3/1882. Not. Scav. в. 40, form 37, diam. I8.6 cm. burnt black.

Ovolo as last, but much blurred. The field is divided into two friezes by the usual wreath. Upper frieze; rinceau, the spaces filled by a small spiral, a larger spiral ending in a rosette and a threeleafed ornament ( $M$ on fig. 4), every second space under the central stem has arrow-heads substituted for the leaves. The same rinceau occurs on nos. 45 and 46 . Lower frieze ; medallion, the whole background being filled with arrow-heads. The medallions are grouped in three sets of three, the middle one containing the eagle of nos. 42, 43 and 45, and the other two, birds left and right as in nos. I9 and 45. A bowl with decoration identical with this except for the small spiral of the rinceau was found at Nijmegen.

45. I I 2993, 102/1882. Not. Scav. в. 28, form 37, diam. $22 \mathrm{~cm}$. Ovolo as last. The field is divided into two friezes by the usual 
wreath. Upper frieze; rinceau as on no. 44. The arrow-heads are not always placed regularly. Lower frieze ; rinceau as on no. 43, but the birds in the medallions are like those of nos. 19 and 44 .

46. I I 2981, 90/1882. Not. Scav. B. 16, form 37, diam. $15.4 \mathrm{~cm}$.

Ovolo as last. Under it a narrow wreath formed of a threeleafed ornament as on no. 38 . Below this a rinceau like that of nos. 44 and 45 , except that for the small spiral is substituted a rosette. Next, a row of rosettes and under them the usual narrow wreath.

47. I12897, 6/1882. Not. Scav. A. 6, form 37, diam. $22 \mathrm{~cm}$. Ovolo as last. The field is divided into three zones by zigzag lines, (I) rinceau consisting of a small spiral, a larger spiral ending in a rosette and a long leaf with rounded point above the central stem and a sceptre-shaped leaf below as on nos. 53 and 55 ; (2) band of S-pattern as on nos. 37 and 39 ; (3) rinceau consisting of a spiral ending in a rosette, a smaller spiral and a round bud. Every sixth space is filled with arrow-heads except once where only three spaces separate them. Both rinceaux resemble those of no. 39 .

48. 11 2921, 30/1882. Not. Scav. A. 30, form 37, diam. 16.8 cm.

Ovolo as last. The field is divided into three zones by zigzag lines, (I) narrow wreath as on no. 50 ; (2) metopes containing alternately a hound, as on no. 75, chasing the hare of nos. 9, 31, 40, 42, $49,5 \mathrm{I}, 6 \mathrm{I}$ and 83 , and arrow-heads, each occurring four times. The columns of arrow-heads vary from I 2 to 4 ; (3) a wreath formed of three-leafed ornament ( $\mathrm{E}$ on fig. 4 ), as on nos. I $3,29,64,65,66,73$ and 80 .

49. I I 2989, 98/1882. Not. Scav. в. 24, form 37, diam. $23.8 \mathrm{~cm}$.

Ovolo as last. The field is divided into two friezes by the usual wreath. Upper frieze; metopes, (I) group of dog chasing a boar (Déch. 837), both occur on no. I2 ; (2) arrow-heads, usually fourteen columns, but in one case nine, in one six columns ; (3) group of dog chasing speckled hare as on nos. 9, 31, 40, 42, 61, and 83. In one group the hare is omitted through a mistake in spacing. Lower frieze ; rinceau, alternate spaces below the central stem are filled with arrow-heads. Above the stem a small spiral, a large spiral ending in a rosette and stems ending in a feathery leaf and a bird. In the alternate lower spaces there is substituted for the bird a small threeleafed ornament. Below, the usual narrow wreath.

50. I I 3006, I I5/1882. Not. Scav. в. 41, form 37, diam. $23 \mathrm{~cm}$.

Ovolo as last. The field is divided into metopes by zigzag lines, (I) above, lion to left, as on no. 36 (Knorr, Rottweil, I9I 2, xi, I) ; below, a cupid to right with outstretched arms; on the left of 
this metope is an upright wreath of shell-like leaves, as on no. $5 \mathrm{I}$; (2) cruciform, in the upper space three-leafed ornament as on no. $5^{\mathrm{I}}$ and dart-shaped leaves; in the side spaces, spear-shaped leaves; in the lower three-leafed ornament (A on fig. 4), as on 80 ; (3) above, a lion to right, as on nos. $14,36,75$, and 77 , below Minerva (Déch. 8I, but smaller). On the right of Minerva a corner curl ending in a sceptre-like leaf, as on nos. 43 and 47 . The metope with the cupid has three similar curls. Below, a wreath as on no. 48 .

51. I 12967, 76/1882. Not. Scav. в. 2, form 37, diam. $22 \mathrm{~cm}$. Ovolo as last. Below it a narrow wreath of shell-like leaves, as on no. 50. Under this are two friezes, the upper, animals separated by grass plant formed by the three-leafed ornament used in the upper space of the cruciform of no. 50. The animals are, (r) lion to right; (2) sitting rabbit, like Déch. 95 I, but smaller ; (3) small dog to left, as on no. 6 (Knorr, Rottweil, I9I 2, vi, II) ; (4) speckled hare, as on $9,3 \mathrm{I}, 40,42,48,49,6 \mathrm{I}$ and 83 ; (5) lion; (6) bear ; the two last as on no. I3, but smaller. This series is repeated, except that the lion of ( $\mathrm{I}$ ) is changed for the hare. Lower frieze; rinceau, above the central stem are two leaves with serrated edges, between them a spiral and over it a bird (Knorr, Rottweil, rgr 2, ix, 7). In the under spaces are alternately a small stag and two dogs to the right, five of each, the eleventh space being filled by the dog of metope 5 above. Below, a narrow wreath as on nos. $36,68,50$.

52. I I 2975, 84/1882. Not. Scav. B. Io, form 37 , diam. I $8 \cdot 5 \mathrm{~cm}$.

Ovolo as last. The field is divided into two zones with a narrow wreath between them. Upper frieze; rinceau, of which the spaces are filled by a small spiral, a spiral ending in a rosette and a stem ending in a small three-leafed ornament ( $\mathrm{N}$ on fig. 4), as on nos. 37 and 38 , cf. nos. 39 and 47 for the general type. Lower frieze; a rinceau beginning and ending in a crater with high handles, and consisting of a spiral ending in a rosette, a smaller spiral and a leaf ornament, as on nos. $4 \mathbf{I}, 42$ and 43 in the two upper spaces; in the three lower the bud (s on fig. 4 ) is substituted for the leaf. This alternates with a group of animals, (I) winged horse to right with rested head; (2) deer to left, as on 53 ; (3) winged horse to left (Déch. 503). Under (2) and (3) as well as over (2) are stems ending in dart-shaped leaf. The tails of the ho:ses are attached to leaves issuing from the craters.

53. I I 2970, 79/1882. Not. Scav. в. 5, form 37, diam. $23 \cdot 3 \mathrm{~cm}$. Ovolo as last. Metopes and divided metopes. Above the metopes wreath formed of three-leafed ornament, and below them a band of ovals as on no. 40. Metopes, ( $\mathrm{I}$ ) divided, above, two boars to left, below, arrow-heads ; (2) design formed of three large leaves and two buds with corner curls ending in sceptre-shaped leaves as 
on nos. 47 and 55 ; (3) divided, above, lion to left, below, ornament of three poppy-heads ( $\mathrm{T}$ on fig. 4) flanked by spirals ending in large rosettes, cf. Knorr, Rottweil, I9I2, xxvii, I ; (4) cruciform, in the upper and lower spaces three-leafed ornament ( $G$ on fig. 4) flanked in the upper by buds, as on the bowl of Paullus from Pompeii (Déch. vol. i, p. 97, fig. 66), the side spaces each filled by two angular leaves as on no. 39 ; (5) divided, above, two deer as on no. 52 to left, below, arrow-heads.

GROUP IV. BOWLS OF FORM 37, PROBABLY BY MOMMO (PLATES XI-XIII, NOS. 54-63).

54. I I 2997, 106/1882. Not. Scav. в. 32, form 37 . diam. I6.8 cm.

Under the decoration, $M O M$ incised in large cursive letters in the mould. Ovolo with tongue ending in three prongs, below it narrow wreath as in bowl in the British Museum (Cat. M. 555, pl. xxv). The field is divided into metopes by zigzag lines, (I) four S-patterns as on no. 6I over four rings; (2) group, on the left a draped figure to the right with left arm raised, on the right, male figure (Déch. 377), as on nos. 35 and 74. Below, narrow wreath of $V$-shaped leaves as on no. 79 .

55. I I 29I I, 20/1882. Not. Scav. A. 20, form 37, diam. I $8 \cdot 8 \mathrm{~cm}$.

Ovolo as last. Below it, wreath as on nos. 56, 57 and 63 . The field is divided by zigzag lines into metopes: (I) cruciform ornament, in the upper space a three-leafed ornament (в on fig. 4) flanked by sceptre-shaped leaves, as on nos. 47 and 53 , in the side sections dartshaped leaves common on the bowls of Mommo, below a heartshaped flower. On each side of this metope is an upright wreath formed of three-leafed ornaments (cf. nos. 50 and 59); (2) medallion containing kneeling archer (Déch. 17I), with leaf ornament behind him (cf. B.M. Cat. M. 536, fig. 1.44). ; (3) divided into three sections, (a) small dog like Déch. 921, with a narrow serrated leaf on each side; (b) two rows of arrow-heads ; (c) sitting rabbit like Déch. 95 I ; on either side upright wreaths as in (I); (4) medallion containing large eagle like Déch. 982 , as on nos. IO, I I and 72, and corner curls ending in dart-shaped leaves. Below, a narrow wreath.

56. I 12916, 25/1882. Not. Scav. A. 25, form 37, diam. $14 \mathrm{~cm}$.

Ovolo as last. Decoration in metopes, (I) swan to right in circle as on nos. $41,42,43$ and 67 , below, two rosettes of ten points, small rosettes in the upper corners; (2) arrow-heads ${ }^{1}$; (3) circle containing small ducks (?) with outstretched necks, as on nos. 61,72 and 74 , below, same rosettes as in (I). Under the metopes a narrow wreath of $\mathrm{V}$-shaped leaves, as on nos. 55, 57 and 63 .

1 By an error this metope has been omitted in the drawing. 
57. 112918, 27/1882. Not. Scav. A. 27, form 37, diam. $17 \cdot 8 \mathrm{~cm}$.

Ovolo as last. The field is divided into two friezes. The upper festoons with tassel ending in four-leafed ornament as on a bowl in the British Museum (Cat. M. 484, p. I3I, fig. I3I) with the same ovolo. The festoons contain the conventional dart ornament left and right. Whole frieze identical with lower frieze of no. 63. Lower frieze; a pair of animals three times repeated and separated by a conventional grass plant, as in Knorr, Rottweil, I9I2, xviii, 2 and 3 ; formed of a four-leafed ornament (I on fig. 4), as on no. 2 and the British Museum bowl. Under the lion to the right are three blades of grass, under the winged horse to the left (Déch. 503a) a single blade. Below, a wreath of $V$-shaped leaves as on nos. 55, 56 and 63 .

58. I I 301 8, I27/1882. Not. Scav. в. 53, form 37, diam. $2 \mathrm{I}^{\cdot} 2 \mathrm{~cm}$.

Ovolo as last. The workmanship is rough and the relief blunt and heavy. Decoration in metopes formed by lines ending in rosettes, (I) hook-shaped tendrils ending in dart-shaped leaves issue from the four corners, the two lower ones being inverted; (2) a draped figure to right as on nos. $3 \mathrm{I}$ and 82 , where he is placed at the same angle as here: facing him, Hercules (?), Déch. 462 : below, two rows of arrow-heads; (3) a pair of gladiators, both so blurred that the details are obscure. The figure on the right is thrusting a spear into the body of the other, who raises his left arm, perhaps in sign of defeat : his legs seem to be protected by large greaves. Below, a wreath formed of a three-leafed ornament.

59. II 29I4, 23/1882. Not. Scav. A. 23, form 37, diam. I6 cm.

Below the decoration traces of stamp (see pp. 30 and 40 above). Ovolo as last. Decoration in metopes with small S-pattern below, (I) divided; above, hare to right; below, diagonal lines and arrow-heads (cf.metope on no. 60) : on each side an upright wreath of fourleafed ornaments (cf. nos. 50 and 55); (2) pair of gladiators (Déch. 601 and 602 or 603 and 604; Knorr, Rottweil, 1912, xi, 2), and two corner curls ending in dart-shaped leaves.

6o. 112987, 96/1882. Not. Scav. в. 22, form 37, diam. $15.5 \mathrm{~cm}$. burnt black.

Ovolo as last. Decoration in metopes, (I) medallion containing cupid to left (Déch. 280), as on nos. 8 and 62; (2) divided; above, dog to right, on each side a zigzag line; below, diagonal lines and arrowheads : cf. 59; (3) medallion as in (I) containing cupid (Déch. 268) to right as on 74 . Metopes (I) and (3) have each four corner curls ending in dart-shaped leaves. The same metopes occur on a British Museum bowl (Cat. M. 555, pl. xxv) and on nos. 5 and $\mathrm{I} 8$ : (2) occurs four times. (I) and (3) twice each. 
6r. I13014, I23/1882. Not. Scav. B. 49, form 37, diam. $20^{\circ} 8 \mathrm{~cm}$.

Ovolo as last. The field is divided into two friezes. Upper frieze; metopes, (1) group of dog and speckled hare, as on nos. 9, 3I, 40, 42,49 and 83 ; (2) arrow-heads; (3) small medallion, as on nos. 2 and 3 , enclosing small bird alternately left and right, as on nos. 56, 72 and 74 . Lower frieze; metopes, (I) animal to right with two corner curls ending in dart-shaped leaves; (2) arrow-heads ; (3) grass plant formed of four-leafed ornament ( $\mathrm{H}$ on fig. 4) as on Knorr, Rottweil, I9r 2, xx, I ; (4) arrow-heads ; (5) panther (?) to left as on no. 2 with a row of arrow-heads below. Lastly, S-pattern as on no. 54 .

62. I I 2906, I 5/1882. Not. Scav. A. I 5, form 37, diam. I8.5 cm.

Ovolo as last. Below it a wreath of ornaments like reversed threes, as on no. 68. The field is divided into metopes by zigzag lines ending in rosettes, and containing alternately a cupid (Déch. 280), as on nos. 8 and 6o, and a lion like Knorr, Rottweil, Igr 2, xi, I, but smaller, alternately to left and right. Below, a wreath of the ornament of three poppy-heads ( $\mathrm{T}$ on fig. 4), which occur commonly, especially on the bowls of Mommo.

63. 1 I 2988. Not. Scav. в. 23, form 37 , diam. $23.8 \mathrm{~cm}$.

Ovolo as last. The field is divided into two friezes by a narrow wreath. ${ }^{1}$ The lower frieze consists of festoons enclosing the conventional dart-ornament to left and right and is identical with the upper frieze of no. 57. Below, a narrow wreath as on nos. 55, 56 and 57. The upper frieze has not been copied. The description in the Notizie reads, "Another with the decoration divided into two zones; in the upper are six compartments, in four of them are represented a winged horse and a running lion, in the fifth a dog and a lion in the act of running, and in the sixth, which is smaller than the others, a winged horse." This description shows that the frieze had a marked resemblance to the lower frieze of 57 , a bowl therefore almost identical with this one.

GROUP V. BOWLS OF FORM 37 BY VARIOUS POTTERS.

(PLATES XIII-XVI, NOS. 64-85).

64. II 2928, 37/1882. Not. Scav. A. 37, form 37, diam. $13 \cdot 8 \mathrm{~cm}$. burnt black.

Ovolo with tongue ending in knob very similar to that of nos. 73 and 74. Below it a wreath formed of the three-leafed ornament (E on fig. 4), as on nos. I3, 29, 48, 65, 66, 73 and 80. Main frieze; metopes divided by zigzag lines ending in rosettes, ( $\mathrm{I}$ ) winged horse as on nos. 32,76 and 80 ; (2) arrow-heads; (3) dolphin as on nos. 66 and 80 .

Misplaced in the drawing. 
65. I I 2998, 107/1882. Not. Scav. в. 33, form 37, diam. I $5.4 \mathrm{~cm}$.

The bowl bears the stamp ofmo reversed, incised on a label among the decoration (see above, p. $4 \mathrm{I}$ ). Ovolo with tongue ending in small knob turned slightly to the left. The same ovolo occurs on a fragment at Nijmegen bearing this stamp. Decoration; rinceau, below the central stem a V-shaped leaf ornament ( $E$ on fig. 4), as on nos. I $3,29,48,64,66,73$ and 80. On each side a small bird, as on no. 72. A row of arrow-heads is separated from this by a zigzag line ending in rosettes, alternately nine arrow-heads and six, the stamp taking the place of the middle three. Above the central stem a large leaf, a crook-shaped tendril (cf. Knorr, Rottweil, I9I2, iv, 5), and a stem ending in the same ornament as occurs between the birds. Below, a narrow wreath.

66. I I 2907, I6/1882. Not. Scav. A. I6, form 37, diam. I $8 \mathrm{~cm}$.

Ovolo as last. Below it a wreath formed of the three-leafed ornament (E on fig. 4) of no. 65. The main frieze consists of metopes divided by zigzag lines ending in rosettes, and containing alternately arrow-heads and a dolphin as on nos. 64 and 80 (Déch. I049 on a bowl with stamp ofMo). Lastly a wreath formed of a three-leafed ornament ( $\mathrm{k}$ on fig. 4 ) as on nos. $3, \mathrm{I} 3, \mathrm{I} 8$ and 29.

67. II 2913, 22/1882. Not. Scav. A. 22, form 37, diam. I $5.7 \mathrm{~cm}$.

Ovolo with tongue ending in three prongs. Under it a narrow wreath of $V$-shaped leaves. The main frieze is divided into metopes by zigzag lines ending in rosettes, ( $\mathrm{I}$ ) notched medallion containing swan to left, the corner of the metope filled with small rosettes; (2) divided metope, above, a dog chasing a boar, below, two rows of arrow-heads; (3) like (I) but with swan to right. The pair of swans are slightly smaller copies of those on nos. $4 \mathrm{I}, 42,43$ and 56 .

68. I I 2898, 7/1882. Not. Scav. A. 7, form 37, diam. $21 \mathrm{~cm}$. (Déch. vol. i, p. 98, fig. 68).

Ovolo with tongue ending in small thistle-shaped knob. Four bands of decoration, (I) reversed threes, as on no. 62 ; (2) corded S-patterns ; (3) wreath of three-leafed ornament (A on fig. 4) as on nos. I8, 24 and 55 ; (4) identical with (2).

68a. II 2901, I0/1882. Not. Scav. A. Io, form 37, diam. $21 \mathrm{~cm}$. Made in the same mould as no. 68.

69. I I 2986, 95/1882. Not. Scav. в. 21, form 37, diam. I3.4 cm.

Ovolo with tongue turned slightly to the left at the tip. The decoration consists of narrow godroons slightly twisted to the left and separated by zigzag lines which meet the horizontal one under the ovolo. 
70. I I 2983, 92/1882. Not. Scav. в. I 8 , form 37 , diam. $16.5 \mathrm{~cm}$.

Ovolo small, with tongue attached to the right side of the egg. Below, a continuous spiral pattern enclosing rosettes. A narrow wreath formed of a three-leafed ornament, of which the details are lost, separates the spirals from a rinceau. The spaces above the central stem contain a heart-shaped leaf (Knorr, Rottweil, 1912, iii, 2) and a fan-shaped leaf (Knorr, Rottweil, I9I2, iv, 6), below the stem the same heart-shaped leaf and a long three-leafed ornament.

71. I I 2985, 94/1882. Not. Scav. в. 20, form 37, diam. I4 cm.

Ovolo with tongue ending in a small knob. The field is filled by a rinceau. Above the central stem a tendril ending in a fan-shaped leaf and the conventional dart-ornament as on nos. 24, 36, 57 and 63 with a rosette to the right. Below the central stem an ornament resembling that of Knorr, Rottweil, 1907, ii, I, with stamp sEver. Below, a wreath of $\mathrm{V}$-shaped leaves.

72. I1 2909, 18/1882. Not. Scav. A. 18, form 37, diam. $16.3 \mathrm{~cm}$.

Ovolo without tongue, small and finely moulded. Rinceau decoration. Above the central stem two large sycamore leaves (cf. Knorr, Rottweil, I9I2, viii, I). They occur also on a bowl of form 29 with the stamp GerMantcF from Pompeii (Inv. I23I 57). At the point where the leaf-stalks meet is a small dart-shaped leaf, as Knorr, Rottweil, I91 2, viii, 4. Above are two small birds, as on nos. 56, 61 and 74. Below the central stem a large eagle (Déch. 982), like those on nos. IO, I I and 55, but slightly larger and more carefully moulded. Under the wings are two small birds facing inwards, as on no. 65 .

73. II 2912, 21/1882. Not. Scav. A. 21, form 37, diam. I7.5 cm. The stamp MEMORIs is placed upside down under the decoration. Ovolo with tongue ending in small knob. The field is divided into metopes by zigzag lines, (I) cruciform; in the upper space a three-leafed ornament ( $E$ on fig. 4), as on nos. I3, 29, 48, 64, 65,66 and 80 , flanked by small narrow leaves ( $Q$ on fig. 4), as on nos. $9, \mathrm{I}_{4}$ and 76 ; in the side spaces tendrils ending in catkins, as on no. 74 ; in the lower space a four-leafed ornament (D on fig. 4); (2) notched medallion containing a cruciform ornament composed of the four-leafed ornament of ( $\mathrm{I})$ : the entire design occurs on a bowl from Pompeii figured by Déchelette (vol. i, p. 98, fig. 67: see above, p. 40) ; (3) repeats (I) ; (4) same medallion as (2) enclosing a cupid (Déch. 353), as on no. 74. Metopes (2) and (4) have each four corner curls ending in the catkins of the cruciform, and enclosing small birds. Metope (I) occurs four times, metopes (2) and (4) twice each. 
74. I I 2894, 3/1882. Not. Scav. A. 3, form 37, diam. $21 \mathrm{~cm}$.

Stamp and ovolo as last. The field is divided into metopes by zigzag lines, (I) medallion, as on no. 73, enclosing a figure of Mercury to the right, with winged cap and shoes, carrying an upright object in his left hand: this figure occurs also on the bowl of Memor at Trier (see p. 36): on each side of the Mercury a tendril ending in a catkin, as on no. 73; (2) cruciform, in the upper space a swan, as on nos. $4 \mathrm{r}, 42,43,56$ and 67 , and two smaller birds, as on $55,6 \mathbf{I}$ and 72 ; in the side spaces catkins; in the lower space a five-leafed ornament. On either side of the metope an upright wreath of $V$-shaped leaves; (3) medallion, as (I), enclosing cupid as in 73 . Metopes ( 1 ) and (3) have each four corner curls ending in catkins; (4) divided; above, a cupid (Déch. 268), as on 60; below, arrowheads ; (5) repeats (2) ; (6) divided ; above, figure to left (Déch. 577), as on nos. 35 and 54 ; below, arrow-heads. The series is repeated to complete the decoration. Below, a band of S-pattern as on the Trier bowl.

75. I I 2923, 32/1882. Not. Scav. A. 32, form 37, diam. $13.5 \mathrm{~cm}$.

Ovolo with tongue ending in knob. It is somewhat blurred, but is of the same form as that of 77 . Decoration in metopes divided by zigzag lines, (I) lion to right, as on nos. I4, 36, 50 and 77 ; above, a snake; (2) five diagonal lines and arrow-heads ; (3) group of a dog, as on no. 48, chasing a stag (Knorr, Rottweil, I9ı 2 , xxiii, 5 and 8), as on 77 : above and below the dog are snakes; (4) arrow-heads. The series is repeated to complete the bowl. In metope (2) of the other series there are four diagonal lines. Below, a narrow wreath of $V$-shaped leaves, as on no. 36. The mould was carelessly made, the diagonal lines crossing and partially obliterating the ovolo.

76. I I 2968, 77/1882. Not. Scav. в. 3, form 37 , diam. $23 \cdot 5 \mathrm{~cm}$. Ovolo with tongue ending in three prongs. Decoration in metopes separated by zigzag lines, (I) Diana and deer (Déch. 63): from the upper angles and the left lower angle spring corner curls ending in dart-shaped leaves; (2) divided; above, a griffin like Déch. 502; below, a deer to the left, as on nos. Io and 32 , beneath it a bird (Déch. I043 or 1044), to the right, a corner curl ending in a dart-shaped leaf ; (3) cruciform; in the upper space three narrow leaves (e on fig. 4), as on nos. 9,14 and 73 ; in the side spaces tendrils ending in dart-shaped leaves : in the lower space a leaf as in the upper, flanked by leaves like those ending the lower corner curls of $80 ;(4)$ divided; above, diagonal lines and arrow-heads; below, a winged horse like Déch. 503a, as on nos. $3 \mathrm{I}, 64$ and $8 \mathrm{o}$, with a corner curl to the right as in (2); below, a wreath of double leaves.

77. I $2969,78 / 1882$. Not. Scav. в. 2, form 37 , diam. $23 \cdot 8 \mathrm{~cm}$. Ovolo as on no. 75. Below it a narrow wreath of $V$-shaped leaves. 
The field is divided into two zones. Upper; rinceau, above and below the central stem a small spiral, a tendril ending in a sceptreshaped leaf ( $\mathrm{R}$ on fig. 4), and the conventional dart-ornament. The whole frieze is identical with that of no. 36 . Lower, animals separated by grass plants formed of the three-leafed ornament, (J on fig. 4), as on no. 36 ; (I) lion to right, as on nos. I4, 36, 50 and 75 ; (2) deer, as on no. 75 ; (3) lion, as in (I) turned to left ; (4) group of a lion eating a man (Knorr, Rottweil, I907, xiv, 11). Under the animals grass is represented by small diagonal strokes. Below, band of S-patterns, as on no. 59 .

78. 112896, 5/1882. Not. Scav. A. 5, form 37, diam. $19 \mathrm{~cm}$.

Ovolo with tongue ending in small rosette. Below a continuous band of S-pattern. The main frieze consists of metopes separated by zigzag lines, (I) a medallion formed of three concentric circles containing a figure seated to the left on a rock caressing a goat (Déch. 537); (2) cruciform, in the upper and lower spaces poppy-heads ( on fig. 4); in the side spaces tendrils ending in dart-shaped leaves; (3) medallion as in (I), enclosing a recumbent animal ; (4) arrowheads. Metopes (I) and (3) have each four corner curls ending in large dart-shaped leaves (cf. no. 60). The cruciform is very similar to that on no. II, and, in spite of the different ovolo this bowl should perhaps be attributed to Mommo.

79. I I 2902, I I/1882. Not. Scav. A. I I, form 37, diam. $19.5 \mathrm{~cm}$.

Ovolo large and coarse with tongue attached to right of egg and ending in small knob. Below, a narrow wreath of $V$-shaped leaves. The main frieze is divided into metopes by zigzag lines, ( $\mathrm{I}$ ) lion to left as on no. 2 , and probably 15 , with rosette above ; (2) diagonal lines and arrow-heads; (3) lion leaping to right; (4) arrow-heads. Below, a wreath of $V$-shaped leaves similar to that on no. 54 .

80. I I 291 5, 24/1882. Not. Scav. A. 24, form 37, diam. I4 cm. Ovolo blurred, but probably the same as that of nos. 65 and 66. Decoration in metopes: ( $\mathrm{I}$ ) medallion enclosing a dolphin, as on nos. 64 and 66, with three rows of arrow-heads below; (2) cruciform, in the upper space a three-leafed ornament similar to that on nos. I 8, 24, and 68, flanked by narrow pointed leaves (Knorr, Rottweil, 191 2, xi, 6), as in the cruciform of no. 76 ; in the side spaces tendrils issuing from the lower angles of the metope and ending in dart-shaped leaves; in the lower space a three-leafed ornament (E on fig. 4), as on nos. $13,29,48,64,65,66$ and 73 ; (3) medallion enclosing a winged horse, as on nos. 31,64 and 76 . The angles of (I) and (3) are filled with corner curls ending above in large heartshaped leaves, below in narrow pointed leaves as above. 
81. I I 2917, 26/1882. Not. Scav. A. 26, form 37, diam. I4.8 cm.

Ovolo with tongue pierced by small circle and attached to the left of the egg. Decoration in metopes divided by zigzag lines, (I) small winged figure to left, apparently playing a double flute: this occurs on a bowl of form 29 of Flavian date with the stamp ofCALvi in the Sels collection at Neuss; (2) arrow-heads; (3) a draped male figure in Phrygian cap seated to left; (4) a group of two birds, of which the larger occurs on no. I ; (5) repeats $(3)$; (6) repeats (I) ; (7) arrow-heads ; (8) repeats (4); (9) arrow-heads ; (I0) repeats (3); (II) repeats (4); (I 2) repeats (3); (I3) arrow-heads ; (I4) repeats (4); (15) arrow-heads. The number of columns of arrowheads varies considerably in different metopes. Below, a wreath of angular leaves (Knorr, Rottweil, 1912, ii, 2).

82. (Number not known). Not. Scav. в. 46, form 37, diam. $21^{\circ} 5 \mathrm{~cm}$. mottled red and black. ${ }^{1}$

Ovolo with tassel ending in three prongs. Below this a wreath formed of double leaves. Decoration in metopes: ( $\mathrm{I}$ ) arrow-heads ; (2) an erotic group, perhaps as Knorr, Fundberichte aus Schwaben, xviii, Taf. iv, II ; (3) arrow-heads ; (4) figure to right with flowing drapery, as on nos. $3 \mathrm{I}$ and 58 . From the top right-hand angle of this metope springs a corner curl ending in three small rosettes. Below, a band of S-pattern.

83. (Number not known). Not. Scav. A. 2 , form 37 , diam. $2 \mathbf{I}^{*} 4 \mathrm{~cm}^{1}{ }^{1}$

Ovolo as in group IIr. Decoration in metopes: (I) divided; above, combat of gladiators (Knorr, Rottweil, I9r2, xi, 2). The figures are separated by a tiny cupid; below, arrow-heads and under them the speckled hare, as on nos. 9, 3I, 40,42, 48, 49, 5I and 6I ; (2) divided; above, a cupid to the left (Knorr, Rottenburg, v, I5), below, arrow-heads; (3) divided; above, erotic group (Knorr, Rottenburg, v, 9), with small bird (Knorr, Rottweil, I9I2, iii, I) in each of the upper corners; below, a dog, as on nos. 9, 3I, 40, 42, 49 and $6 \mathrm{r}$. Below, is the narrow wreath characteristic of this group.

84. I I 2991. Not. Scav. в. 26, form 37, diam. $23 \mathrm{~cm}$.

Not copied. The description in the Notizie reads, "Another with large frieze in eight compartments, in which are repeated these four representations : (I) a man with a dog at his feet standing and holding in his hand a boar's head (?) ; (2) a cupid who, with raised arms, holds a crown or bird, and below two birds; (3) two gladiators in the act of fighting, one armed with a trident, the other with sword and shield ; (4) a wrestler.

1 This bowl, owing to its decoration, was not
available for a complete examination, and conse- quently the numbers affixed to it could not be ascertained. 
64

A HOARD OF SAMIAN WARE FROM POMPEII.

Group (I) is clearly the Bacchus of Déch. 302, while (2) is perhaps Déch. 479 .

85. I1 2908, I7/1882. Not. Scav. A. 17, form 37, diam. 16. $5 \mathrm{~cm}$.

No notes were made of this bowl. The description in the Notizie reads, "Another similar, with decorations among which two boars and two dogs in flight, and with trophies of spears." The first part of the description clearly suits such a frieze as that of no. I 2 . 


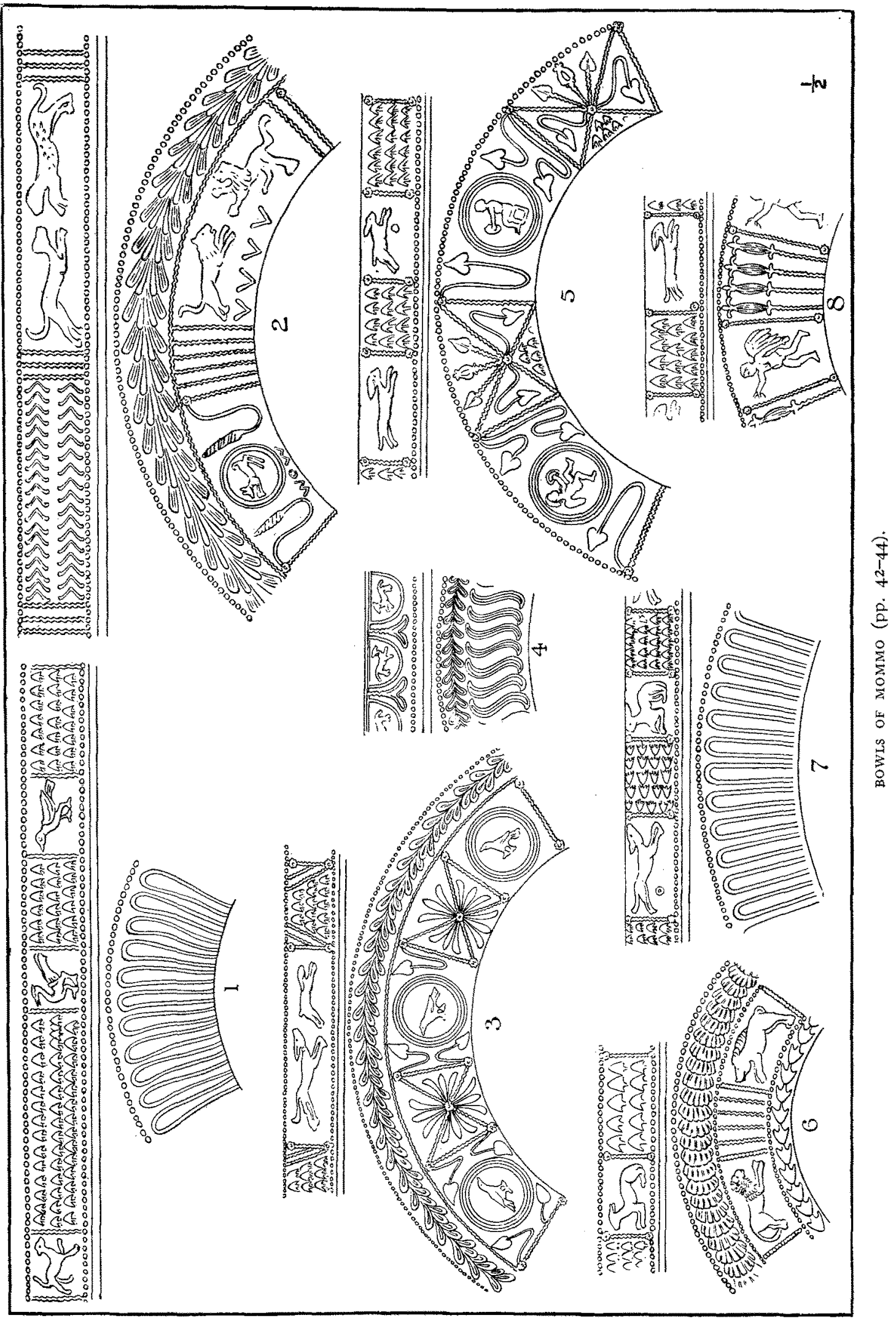




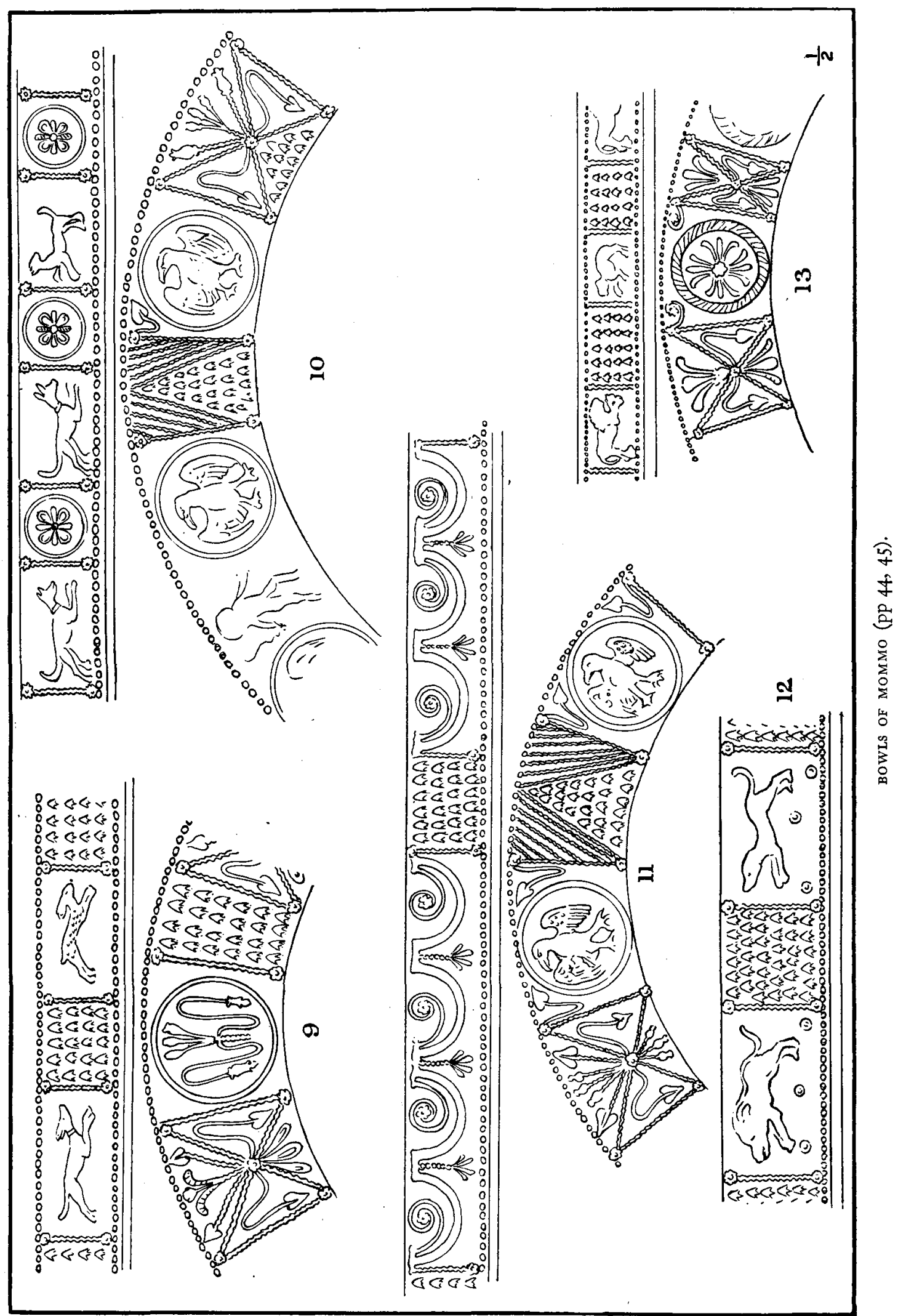




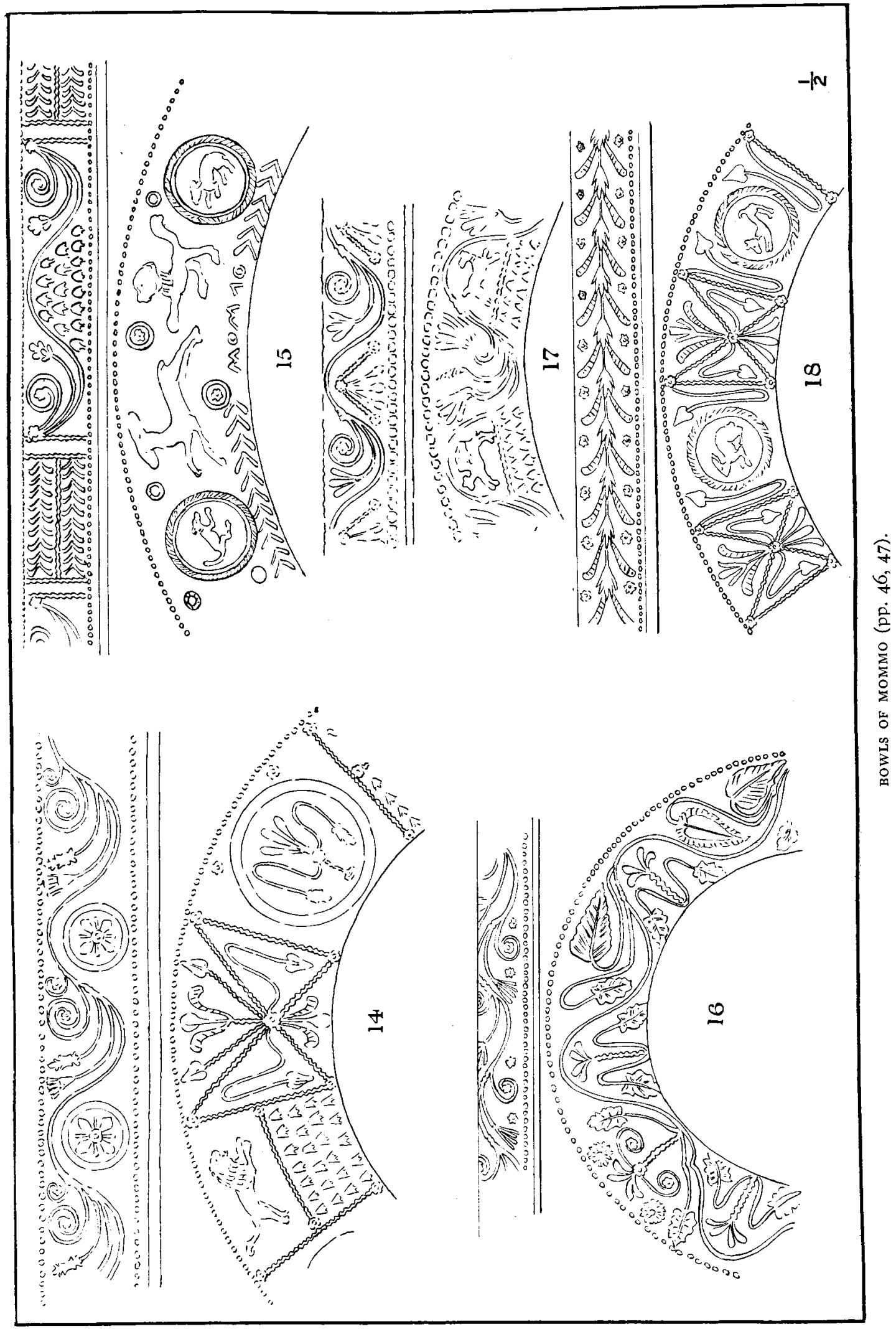



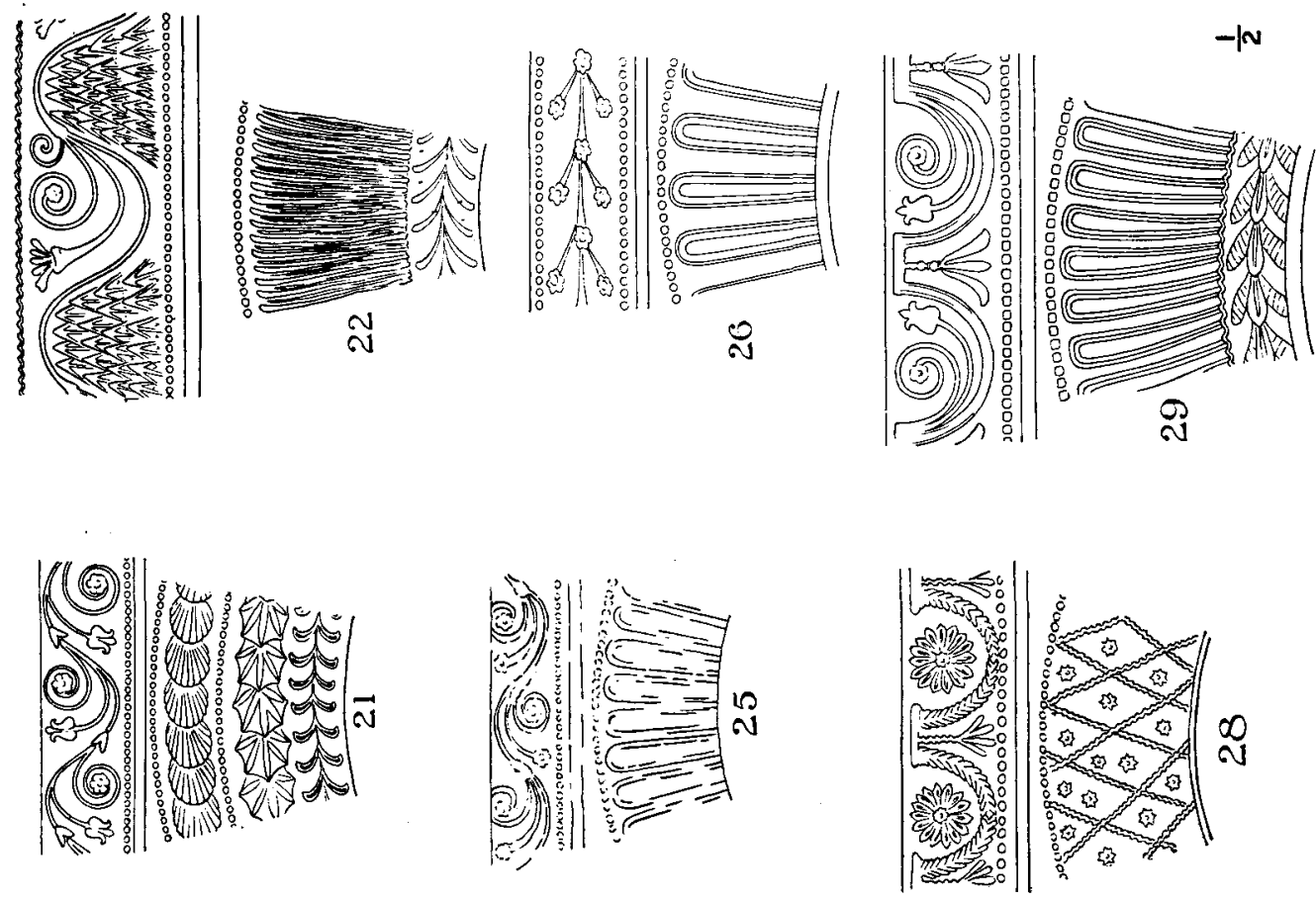

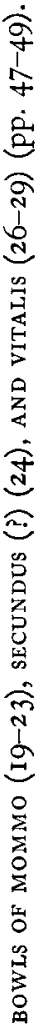
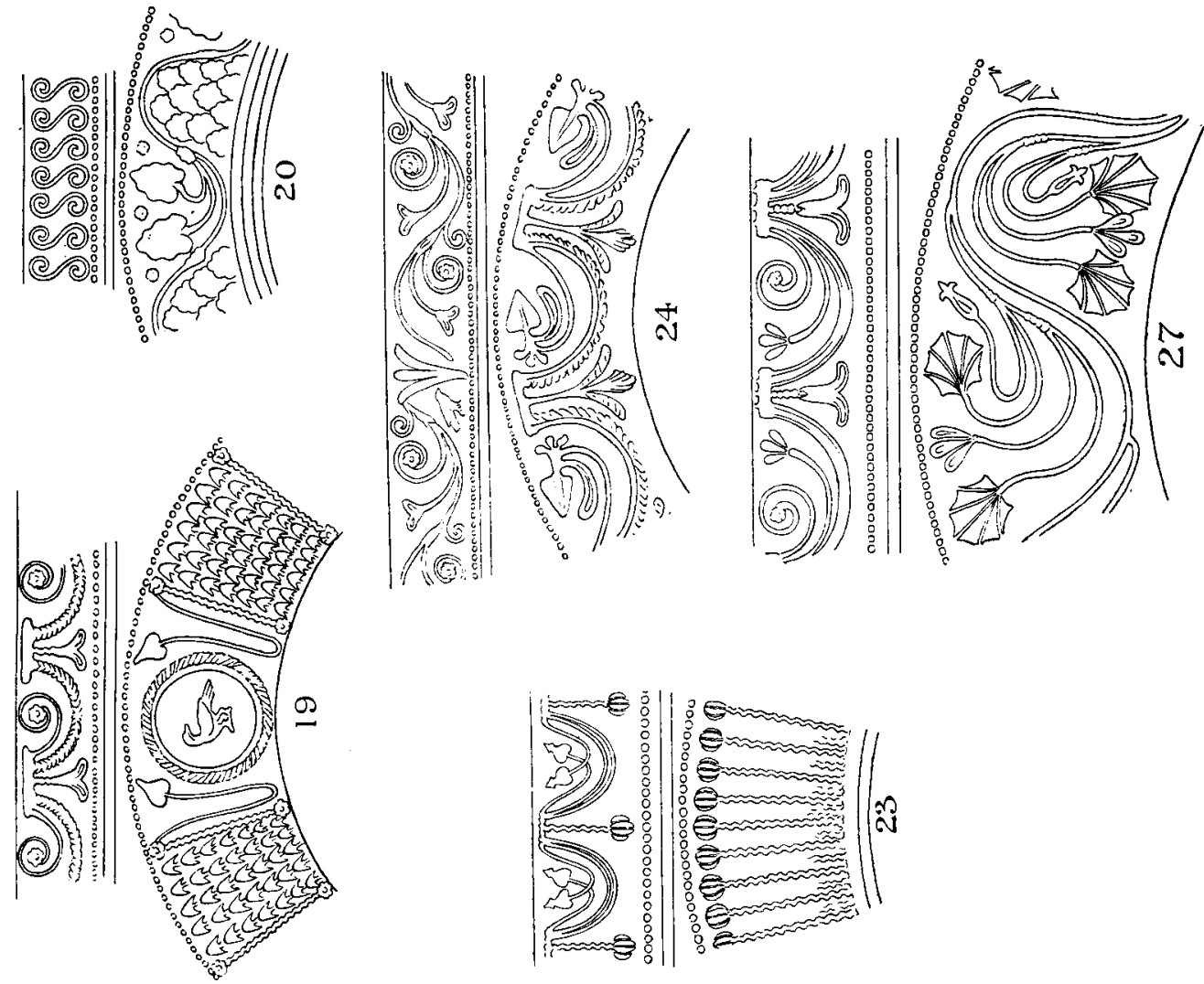

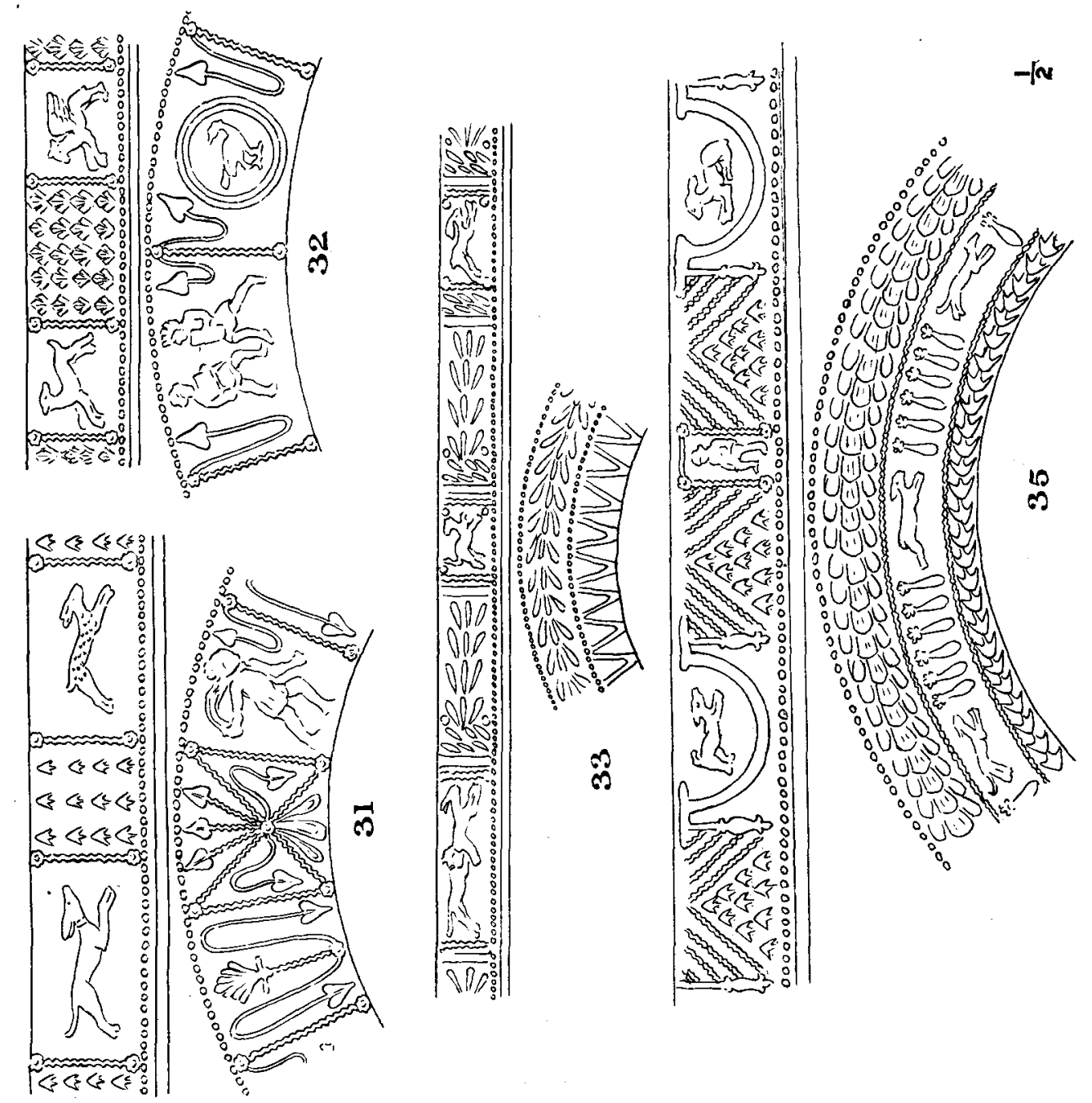

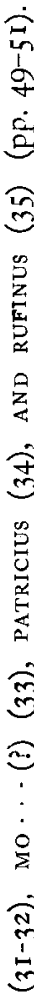


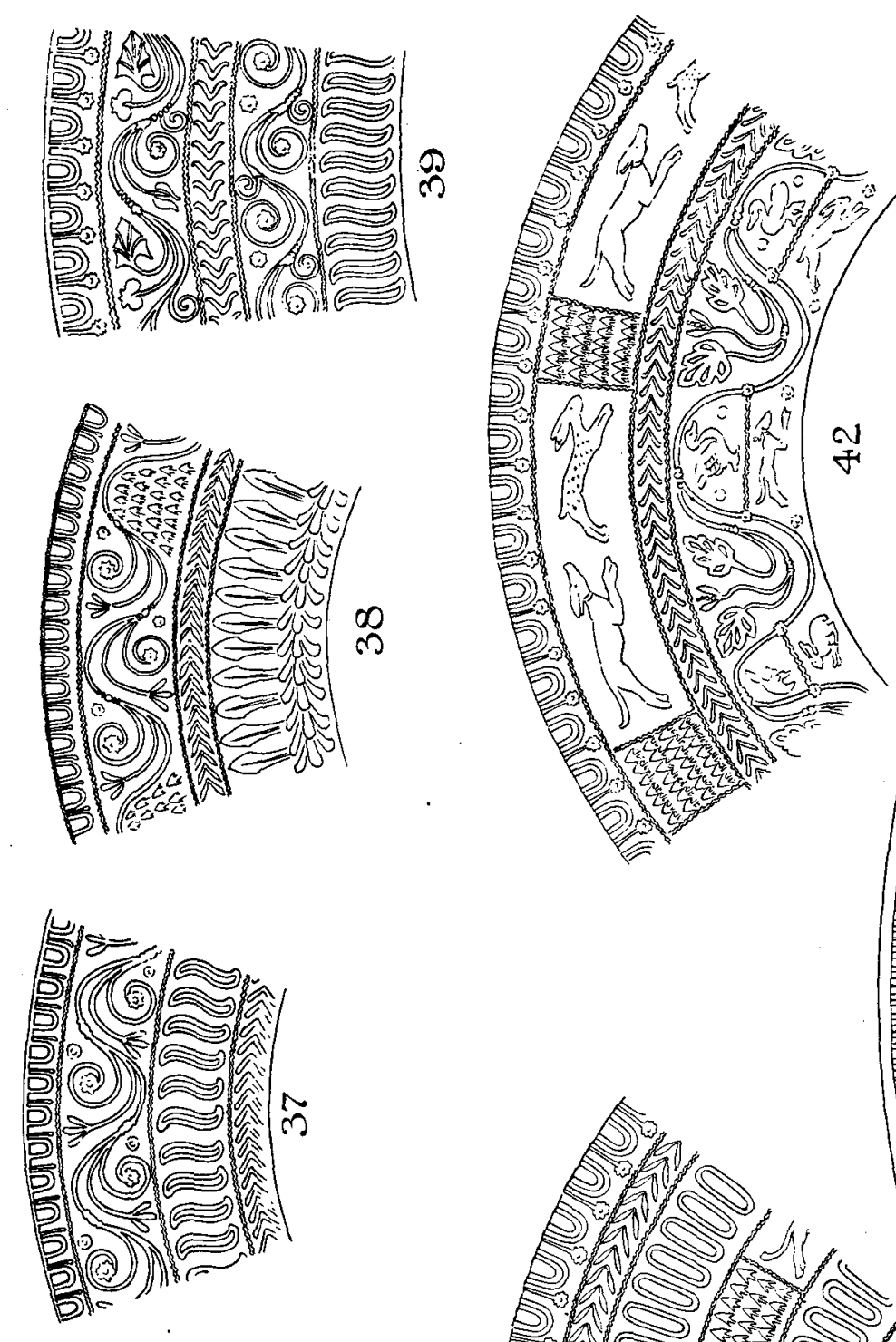

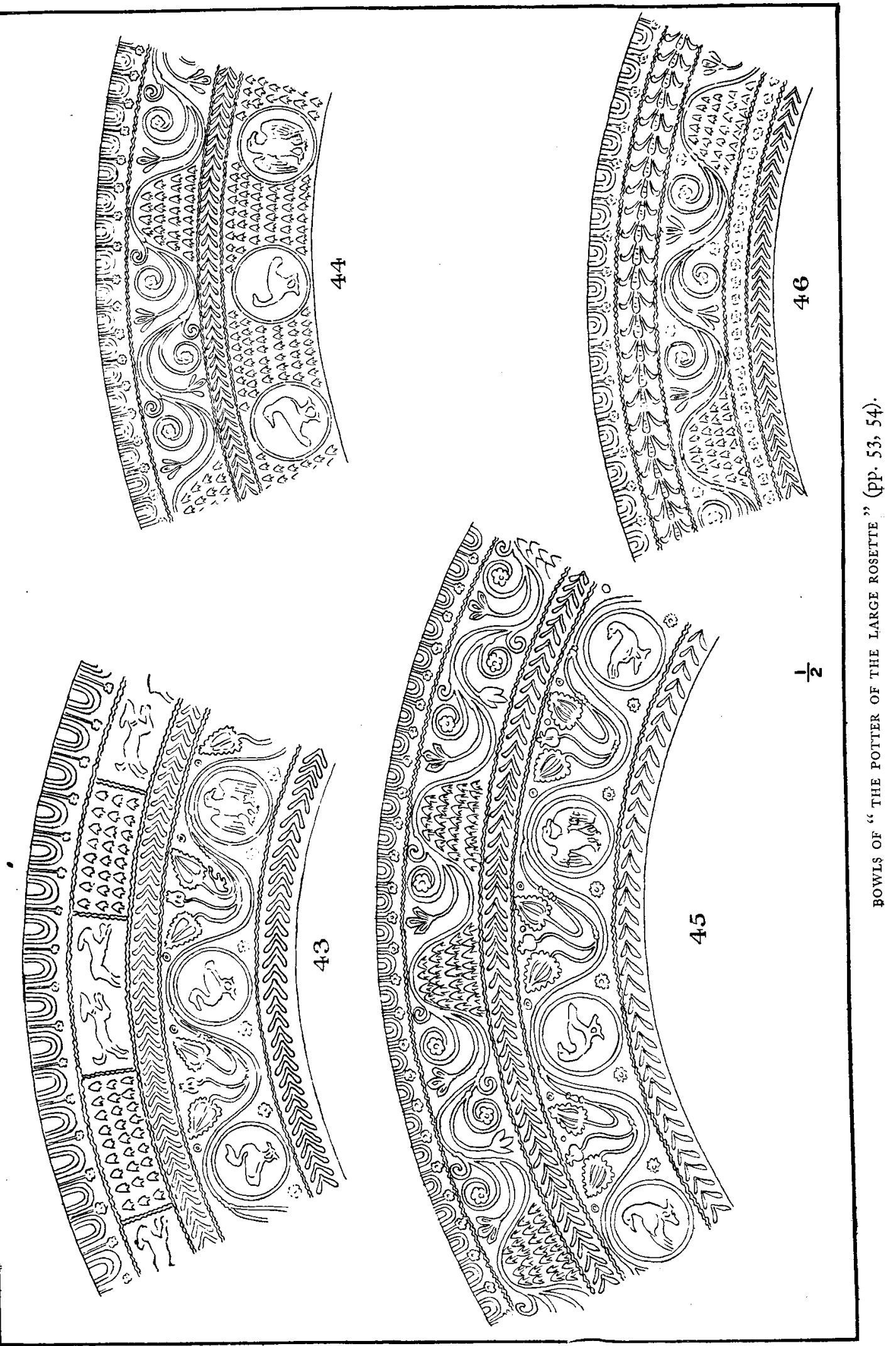


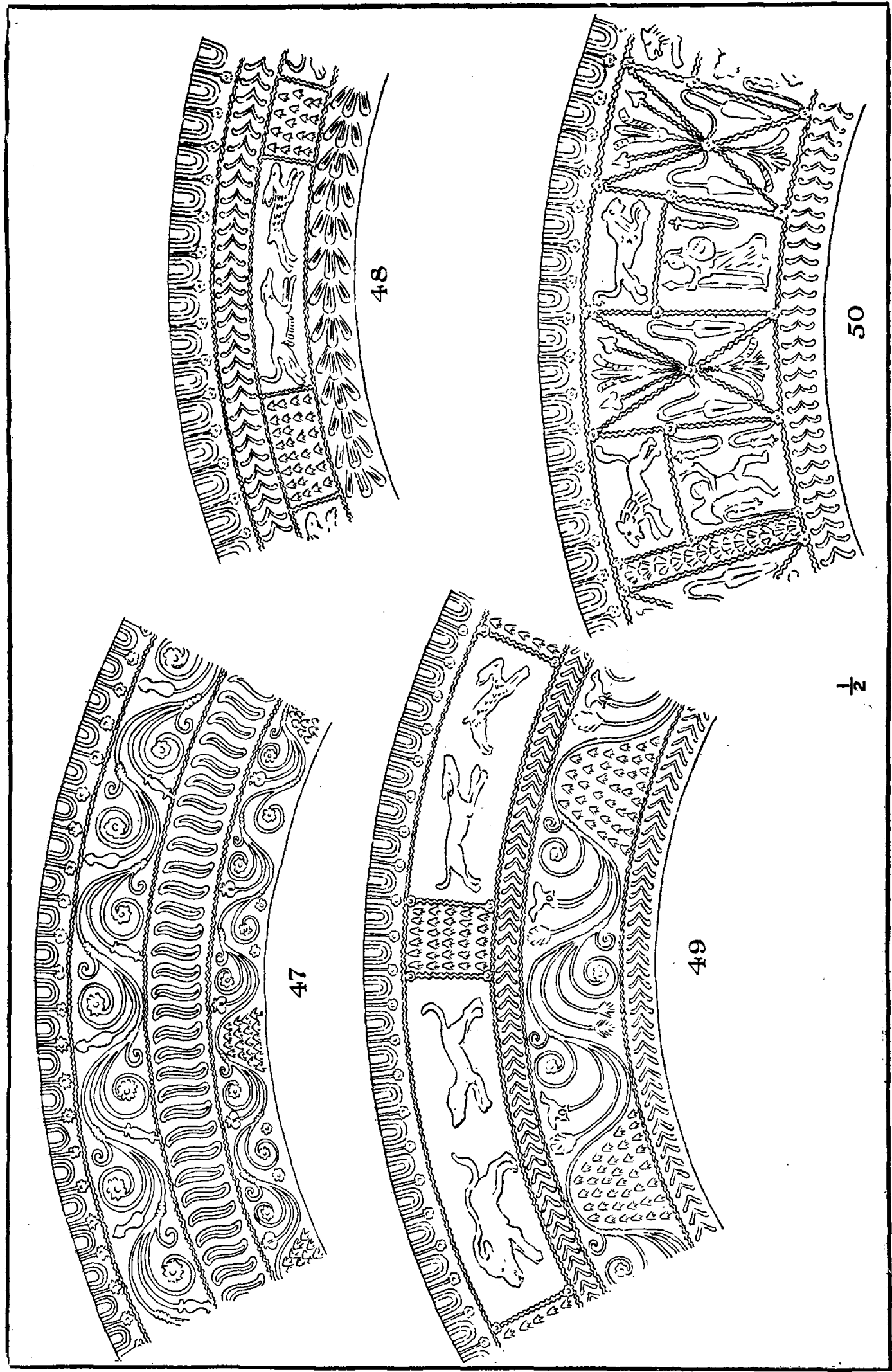




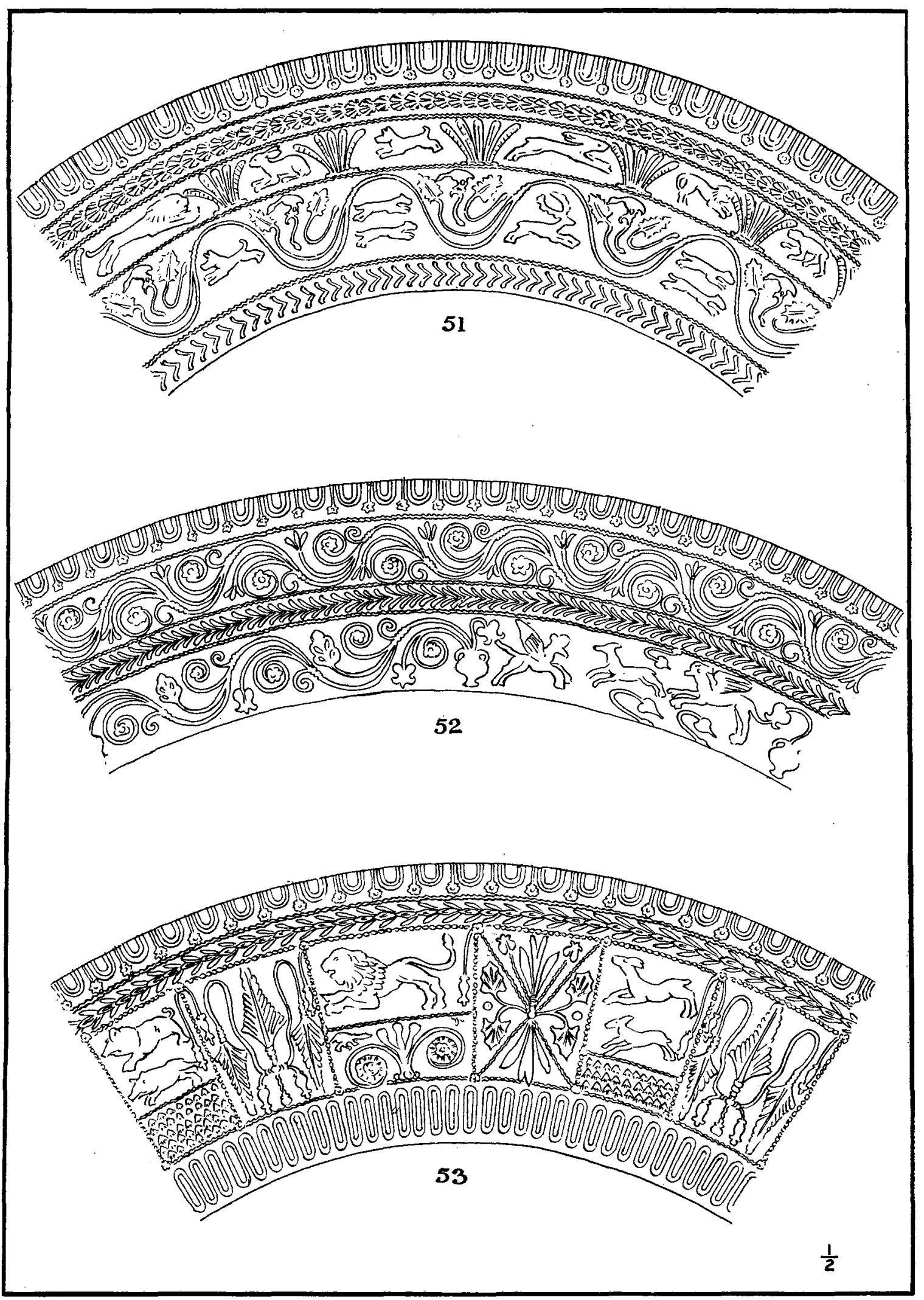

BOWLS OF "THE POTter OF THE LARge ROSETte" (Pp. 55, 56). 


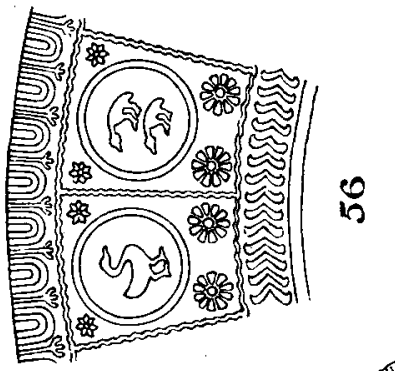

D) 20 Y

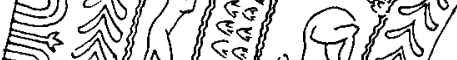

E) 武

S3 0 (n)

D) A 3

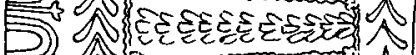

5)

P)

E) $A$ (Gir)

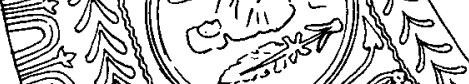

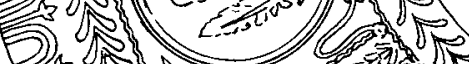

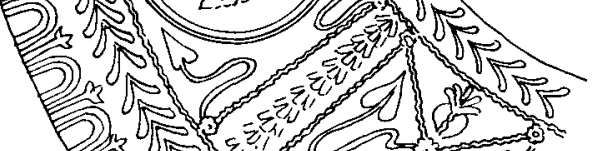

in

(3)

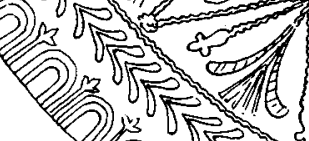

(2) jo

作

(2) 3013

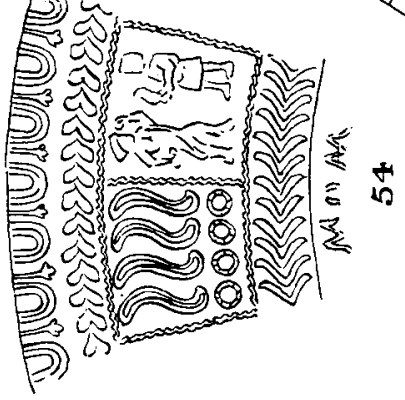

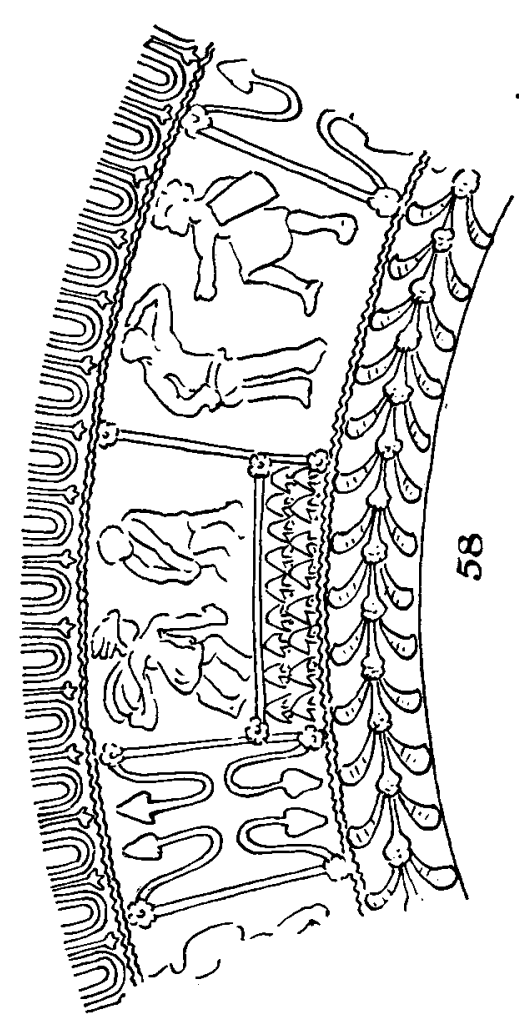

$\infty$

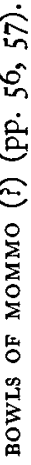




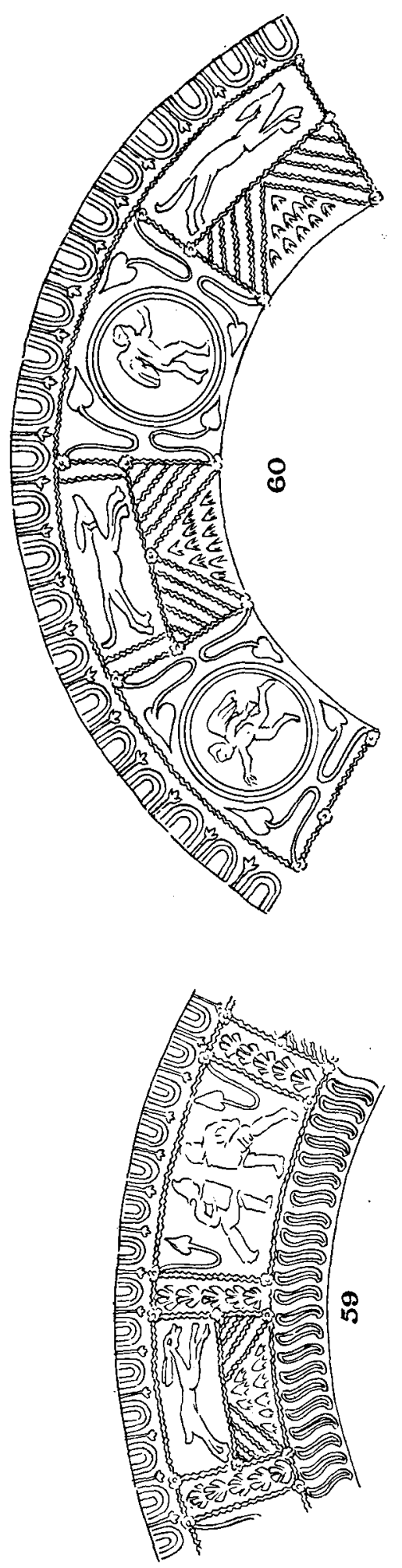

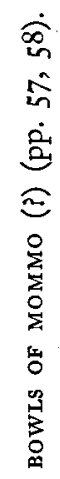




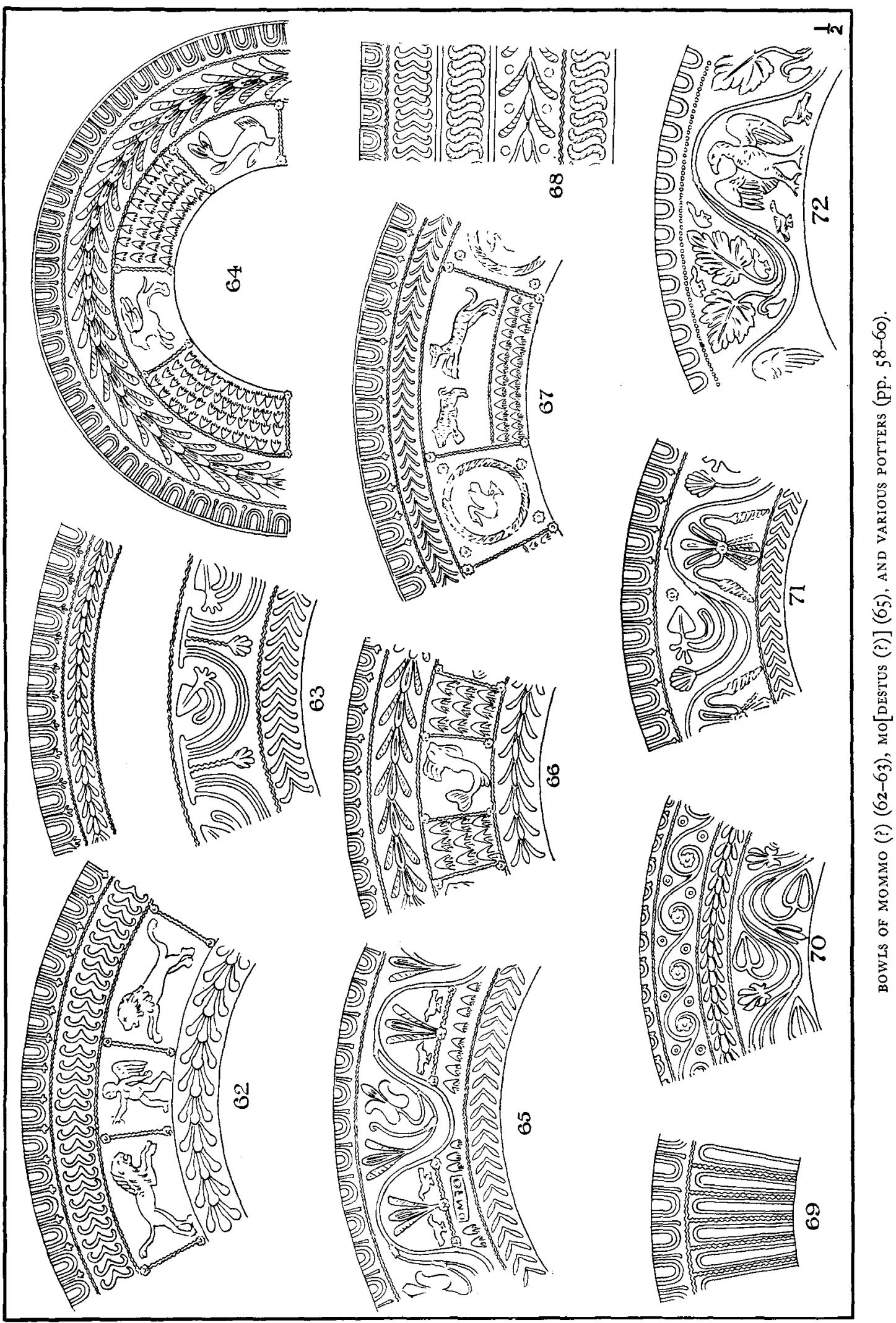




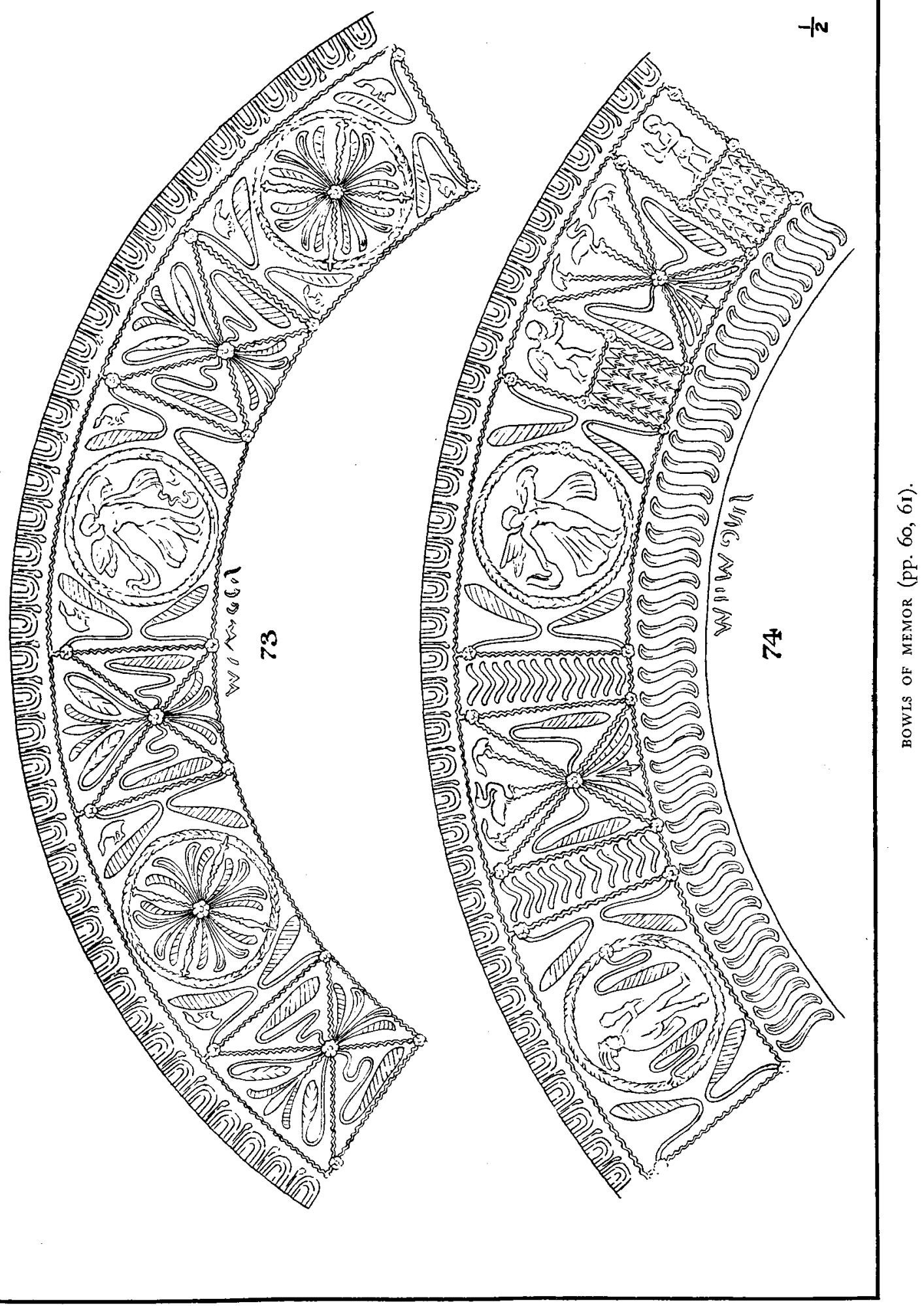




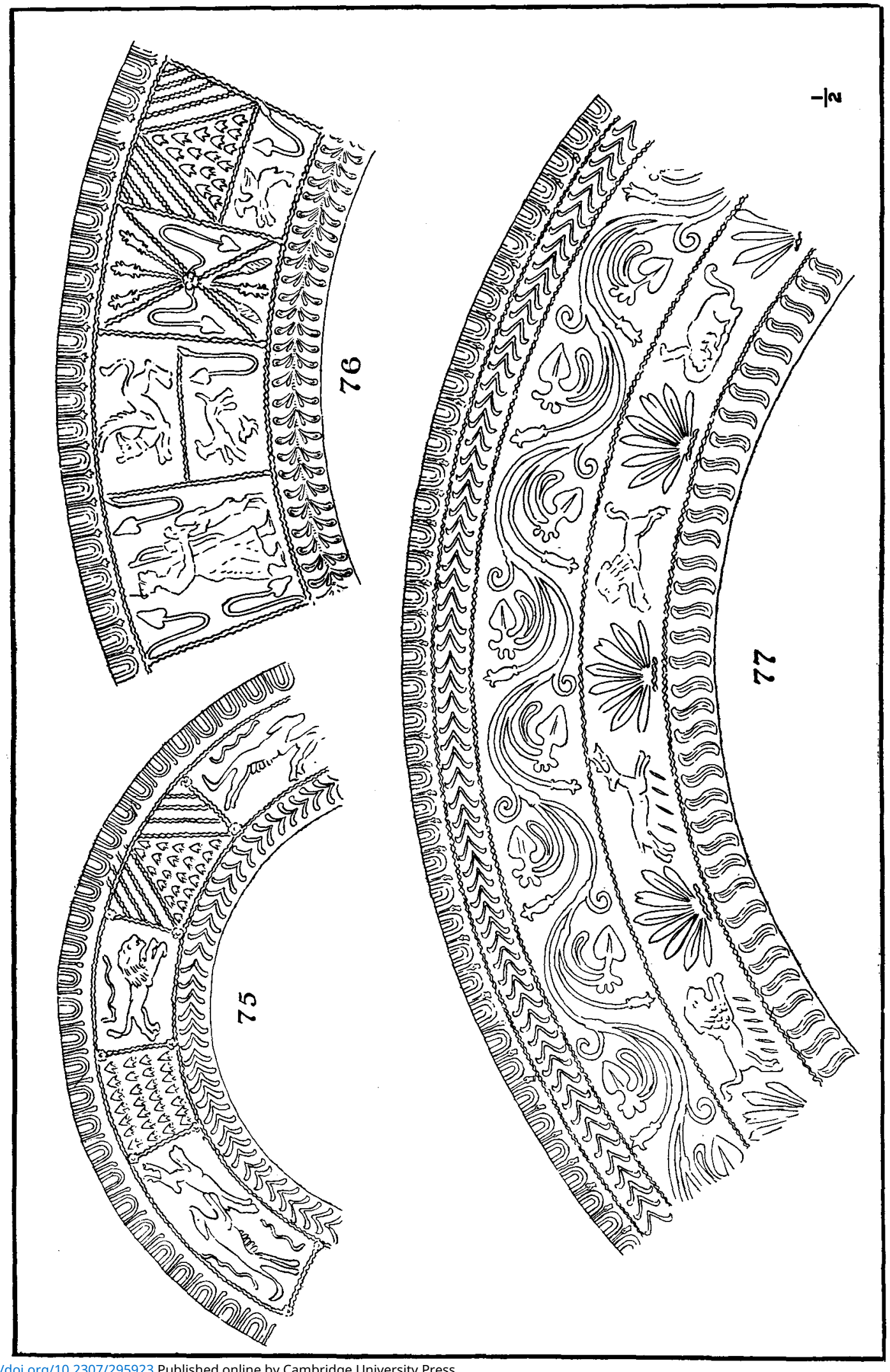

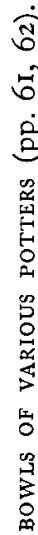




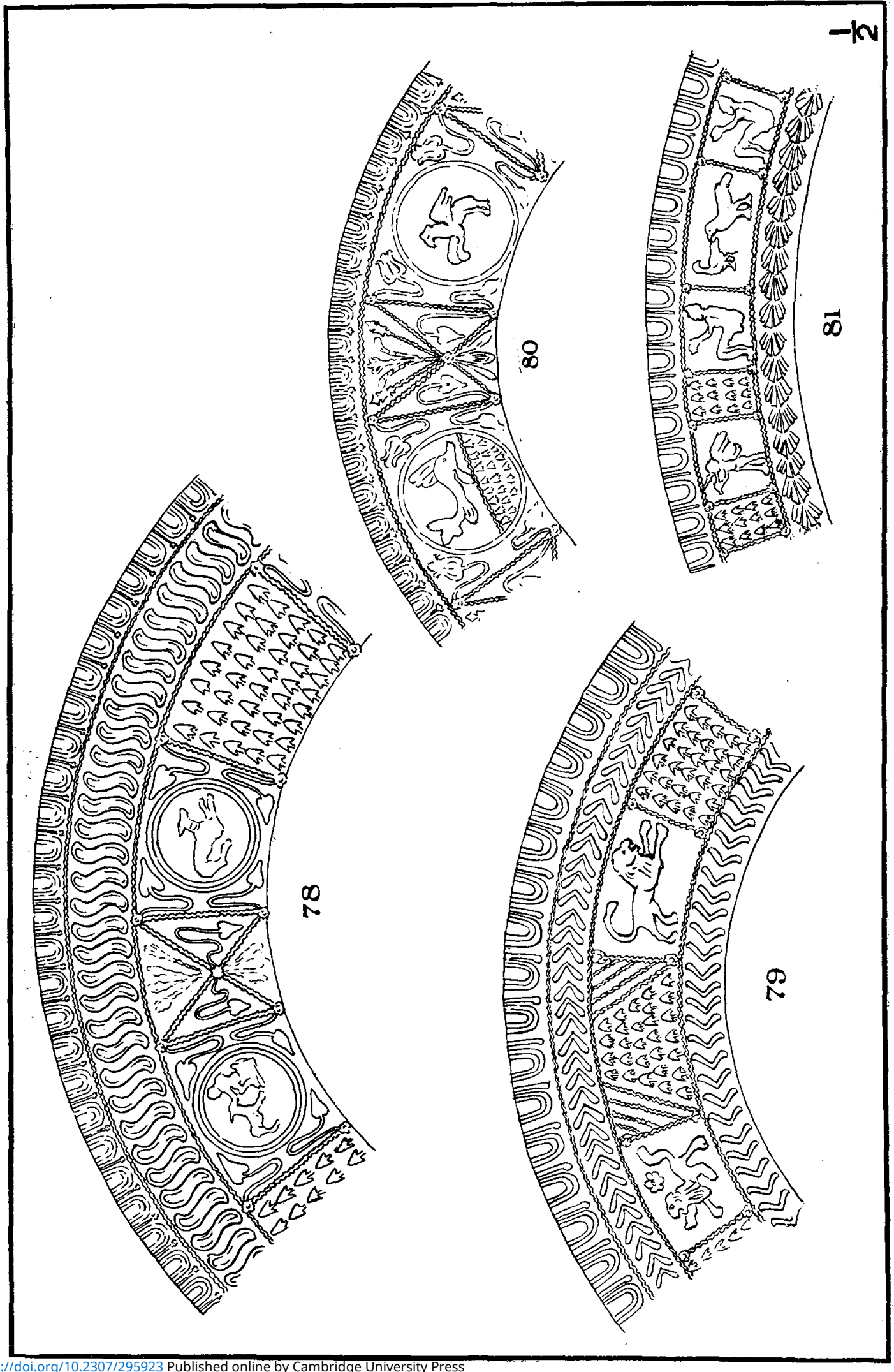

